\title{
AVALIAÇÃO DA INCIDÊNCIA DE CETOSE EM VACAS LEITEIRAS
}

\author{
ERNANI PAULINO DO LAGO \\ Médico Veterinário
}

Orientador: Prof. Dr. VIDAL PEDROSO DE FARIA

Dissertação apresentada à Escola Superior de Agricultura "Luiz de Queiroz", da Universidade de São Paulo, para obtenção do título de Mestre em Agronomia. Àrea de concentração: Ciência Animal e Pastagens.

\section{PIRACICABA}

Estado de São Paulo - Brasil

Fevereiro de 1997 
Dados Internacionais de Catalogação na Publicação (CIP) DIVISĀO DE BIBLIOTECA E DOCUMENTAÇÃO - Campus "Luiz de Queiroz"/USP

Lago, Ernani Paulino do

Avaliação da incidência de cetose em vacas leiteiras / Ernani Paulino do Lago. Piracicaba, 1997.

88p. : il.

Dissertação (mestrado) - Escola Superior de Agricultura Luiz de Queiroz, 1997.

Bibliografia.

1. Cetose 2. Distúrbio metabólico 3. Lactação 4. Produção leiteira 5. Vaca holandesa 6. Vaca leiteira I. Título. 


\title{
AVALIAÇÃO DA INCIDÊNCIA DE CETOSE EM VACAS LEITEIRAS
}

\author{
ERNANI PAULINO DO LAGO
}

Aprovado em: 30 de Abril de 1997

Comissão julgadora:

Prof. Dr. Dr. Vidal Pedroso de Faria ESALQ/USP

Prof. Dr. Wilson Roberto Soares Mattos ESALQ/USP

Prof. Dr. Paulo de Figueiredo Vieira UNESP/Jaboticabal

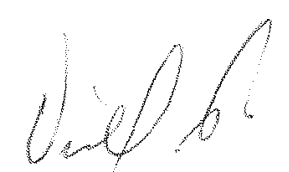

Prof. Dr. Vidal Pedroso de Faria Orientador 
A Deus por estar sempre comigo.

À minha mãe Maria Julia, que significa amor e felicidade na minha vida.

Ao meu pai, meus irmãos, cunhados e sobrinhos, pelo carinho e pelo apoio. $\dot{A}$ Joceli, pelo amor e pelo incentivo. 


\section{AGRADECIMENTOS}

A Universidade Federal de Viçosa e ao Departamento de Veterinária, pela oportunidade de realização deste treinamento.

À ESALQ/USP e ao Departamento de Zootecnia, pela oportunidade de realização deste curso.

À FAPESP pelo financiamento do projeto.

Ao Dr. Vidal Pedroso de Faria, pela amizade e orientação.

Ao Dr. Alexandre Vaz Pires e Dra. Ivanete Susin, pela valiosa colaboração e amizade constantes.

Aos professores Valdomiro Shigeru Myada e Irineu Humberto Packer, pelo apoio e conselhos.

Aos Drs. José Manoel Simas e Cyro Meireles.

A todos os professores do Departamento de Zootecnia Aos amigos Rhainer, César, Cléo e Regina.

Aos proprietários e funcionários da Fazenda Pinhalzinho, onde foram realizadas a colheita de material.

A todos que, direta ou indiretamente, contribuíram para a realização deste trabalho.

E, com carinho: à minha mãe e à Joceli, pelo amor que sempre me dedicaram, e por estarem sempre comigo nos momentos mais difíceis. 


\section{SUMÁRIO}

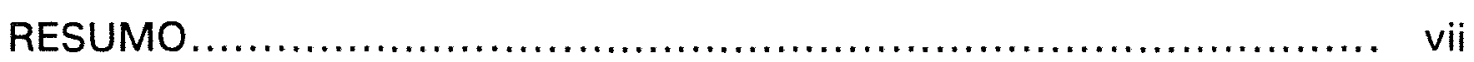

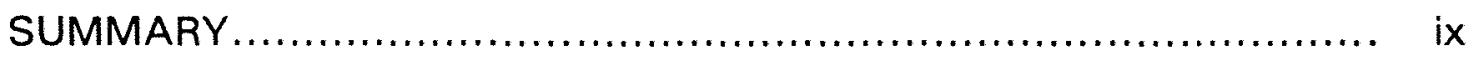

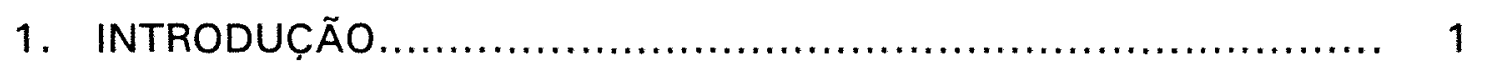

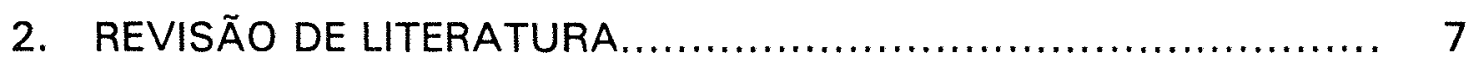

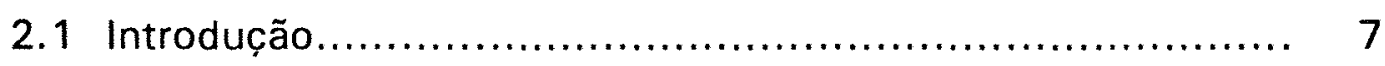

2.2 Considerações sobre cetose de vacas leiteiras.................. 8

2.2.1 Efeitos da cetose na produção de leite............... 11

2.2.2 Efeitos da cetose na performance reprodutiva........ 15

2.2.3 Relação com outras doenças........................ 16

2.3 Avaliação de transtornos no metabolismo energético da

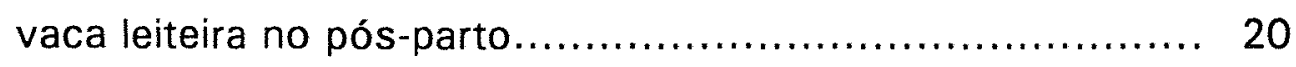

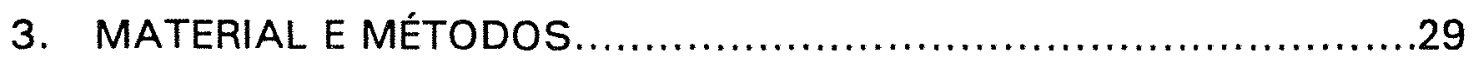

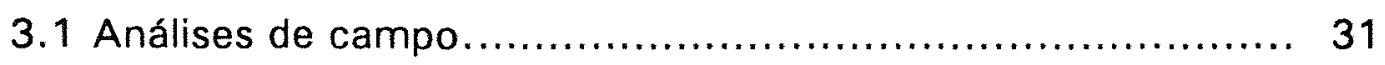

3.2 Análises de laboratório................................... 31

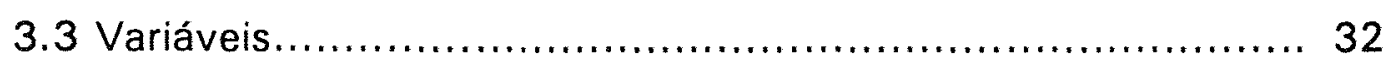

3.4 Análise estatística...................................... 33 
4. RESULTADOS E DISCUSSÃO ...................................... 34

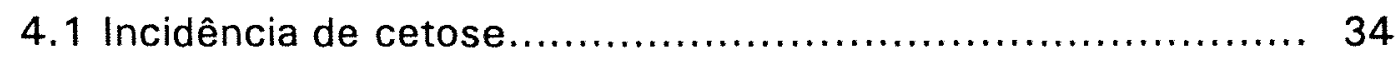

4.2 Avaliação do efeito de BHBA ................................. 36

4.3 Avaliação do efeito da condição corporal ao parto.............. 39

4.4 Avaliação do efeito de perda de peso.......................... 41

5 CONCLUSÕES................................................. 43

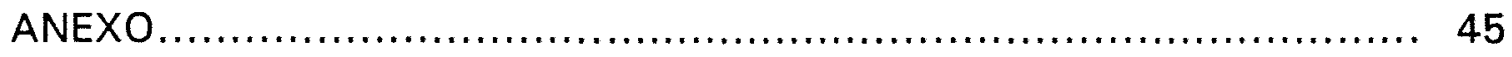

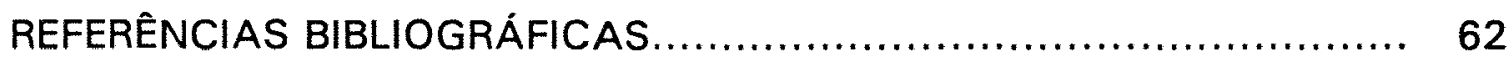

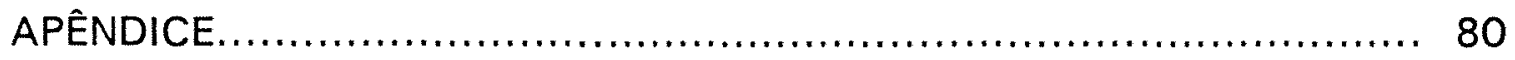




\title{
AVALIAÇÃO DA INCIDÊNCIA DE CETOSE EM VACAS LEITEIRAS
}

\author{
Autor: ERNANI PAULINO DO LAGO \\ Orientador: Prof: Dr. VIDAL PEDROSO DE FARIA
}

\section{RESUMO}

Um estudo foi conduzido com o objetivo de avaliar a incidência de cetose em vacas leiteiras no início da lactação através da análise de betahidroxibutirato (BHBA), glicose e aspartato-aminotransferase (AST) no plasma. Os efeitos de BHBA, condição corporal e perda de condição corporal sobre a performance lactacional e o uso de testes de campo para monitorar vacas com cetose também foram avaliados. Cento e dezoito vacas holandesas de um rebanho comercial, que pariram entre 5 de fevereiro a 24 de junho de 1996 , foram estudadas com relação à ordem de lactação, produção de leite, teor de gordura e presença de corpos cetônicos $(\mathrm{CC})$ no leite, peso e condição corporal, níveis plasmáticos de BHBA, glicose e AST durante as oito primeiras semanas de lactação. Também foram observadas as doenças que ocorreram neste período. A cetose subclínica foi observada em 16 animais, representando $13,5 \%$ da amostra, sendo que apenas um caso evoluíu para a forma clínica. O pico de incidência ocorreu na primeira e segunda semanas de lactação com tendência a ser maior em vacas mais velhas. Os testes de campo foram eficientes para detectar a maioria dos animais com cetose, exceto na primeira semana de lactação. O escore de condição corporal (ECC) ao parto não afetou a produção de leite e a incidência de doenças no período pós-parto. Todavia as vacas que tiveram intensa mobilizaçao de reservas corporais (avaliada através da perda de mais de $40 \mathrm{~kg}$ de peso vivo e $1 \mathrm{ECC}$ ), tiveram significativamente menor produção de leite e maior incidência de cetose e problemas de casco, sendo esta portanto, mais prejudicial do que a própria 
condição corporal ao parto. BHBA maior que $10 \mathrm{mg} / \mathrm{dl}$ afetou negativamente a produção de leite no início da lactação porém seus níveis não estiveram associados às doenças que ocorreram neste período. Em conclusão, o ECC ao parto não afetou a performance das vacas no pós-parto, entretanto grande mobilização de reservas aumentou a incidência de cetose e reduziu a produção e leite. Assumiu-se que a cetose esteja ocorrendo com incidência semelhante em vários outros rebanhos que adotam o mesmo nível de manejo, conforto e práticas de alimentação que o do rebanho estudado, e foi sugerido que o supercondicionamento das vacas ao parto deve ser evitado. 


\section{INCIDENCE OF KETOSIS IN DAIRY COWS: EVALUATION}

Author: Ernani Paulino do Lago Adviser: Prof. Dr. Vidal Pedroso de Faria

\section{SUMMARY}

A survey was conducted to determine the incidence of energetic metabolic disorders in dairy cows on early lactation using blood levels of $\beta$ Hidroxibutiric acid (BHBA), glicose, and Aspartate-aminotransferase (AST). The effects of BHBA levels, body condition score (BCS) and body condition loss on lactation performance were determined. A field test to identify ketotic animals was also used. One hundred and eighteen Holstein cows from a commercial heard, calving from February 5 and June 24 of 1996 were used during the first 8 weeks post partum. Data was collected for parity, milk production, milk fat content, ketones in milk, body wight and condition score, plasma levels of BHBA, glicose e AST. The incidence of diseases was also monitored. Subclinical ketosis was observed in $16(13.5 \%)$ animals. One animal developed clinical signs. Peak incidence occurred in the first two weeks of lactation with older cows being the most affected. The field test was efficient in detecting most ketotic animals except in the first week post partum. BCS at parturition did not affect milk production nor incidence of diseases post partum. However cows with high mobilization of body reserves produced less milk and had a higher incidence of ketosis, and hoof problems indicating that BCS loss is a better predictor of the incidence of disorders then the absolute value. BHBA values grater then $10 \mathrm{mg} / \mathrm{dl}$ decreased milk production on early lactation but was not associated to other problems during the period. In conclusion, BCS at parturition did not affect cows performance 
pospartum; however, mobilization of body reserves ( $>40 \mathrm{~kg}$ and $>1 \mathrm{BCS}$ ), increased incidence of ketosis and reduced milk production. Was assumed that incidence of ketosis are similar to other herds with similar management, nutrition and animals comfort, and was suggest that overconditioned cows at parturition must be avoided. 


\section{INTRODUÇÃO}

Nos últimos anos o número de fazendas que exploram a pecuária leiteira utilizando sistema de confinamento total tem aumentado consideravelmente no país. Dessa forma tem havido maiores investimentos em melhores instalações e equipamentos e também tem sido observado grande aumento nos custos com alimentação. Obviamente para justificar esses investimentos estão sendo selecionados animais de alto valor genético para que altas produções sejam obtidas, e, é natural de se esperar que esse avanço tecnológico deva continuar no futuro.

Em nosso entendimento a habilidade da vaca leiteira em produzir grandes quantidades de leite é governada principalmente pela sua capacidade genética, conforto, práticas de alimentação e qualidade dos alimentos. No que se refere às práticas de alimentação desses animais, muitas mudanças tem sido observadas e nos últimos 10 anos valiosos progressos tem sido alcançados. Todavia a perfeita alimentação de uma grande produtora de leite no início da lactação ainda permanece um desafio para os pesquisadores devido às grandes mudanças hormonais e metabólicas experimentada pela vaca neste período.

Normalmente uma boa alimentação da vaca no período seco pode ser alcançada sem dificuldade e geralmente consegue-se que ela acumule reservas corporais para iniciar a lactação; inclusive em muitos rebanhos se observa vacas excessivamente gordas, o que pode ser prejudicial à saúde das mesmas. 
Ao aproximar-se o parto há uma redução dramática no consumo de matéria seca, (Bertics et al. 1992, Grant et al. 1995, Grummer, 1995), e parte das necessidades em energia e proteina precisam ser supridas pela mobilização das reservas corporais. Após o parto essa situação se agrava nítidamente devido a demanda súbita de nutrientes para a produção de leite sem que haja um devido aumento na capacidade de ingestão de matéria seca (MS). Assim, é inevitável que haja um déficit energético nesta fase, a lipólise sobrepõe significativamente a lipogênese levando a uma grande e rápida mobilização das reservas corporais que se traduz em um estresse metabólico. Essa situação prejudica ainda mais o consumo de MS, afeta a produção de leite e a saúde geral, tornando as vacas mais susceptíveis a transtornos metabólicos e a doenças infecciosas.

A despeito da grande quantidade de gordura mobilizada, o aporte de glicose pode ainda ser insuficiente para atender a grande demanda da glândula mamária, havendo assim uma oxidação incompleta dos ácidos graxos liberados para o metabolismo hepático, com conseqüente aumento na formação de corpos cetônicos (CC).

Os niveis de $\mathrm{CC}$ circulantes tem sido correlacionados positivamente com aumento nos níveis plasmáticos de ácidos graxos não esterificados (AGNE), e baixos níveis plasmáticos de glicose, além da redução na performance geral. Isso leva a concluir que os $\mathrm{CC}$ podem ser utilizados para auxiliar na identificação dos animais que estejam experimentando transtornos no metabolismo energético.

Transtornos no metabolismo energético, caracterizados por altos níveis de $\mathrm{CC}$ circulantes definem uma condição também conhecida como cetose dos ruminantes. Este termo cetose tem sido muito criticado e apontado como sendo um nome inadequado para definir um quadro metabólico que também inclui redução na disponibilidade de carboidratos, aumento no 
metabolismo de lipídios e mudanças hormonais (Bergman, 1970). De fato, durante o período em que a vaca passa por transtornos no metabolismo energético, a hipercetonemia é somente um distúrbio bioquímico que ocorre entre as várias mudanças metabólicas observadas. A hipercetonemia propriamente dita pode ocorrer também em várias outras situações como jejum prolongado, dietas pobres em carboidratos e ricas em gorduras, situações de estresse, anestesia e redução na função hepática (Wakil e Bressler, 1962), e também pode ocorrer em fêmeas de varias outras espécies (Bergman e Sellers, 1960). Em nosso entendimento, analizando corretamente as características metabólicas de transtornos no metabolismo da energia, pode-se sugerir então que na verdade a cetose de vacas leiteiras no pós-parto se trata de uma síndrome, todavia o termo cetose ainda é utilizado por ser ainda bastante aceito no meio científico (Nielen et al. 1994, Gustafsson et al. 1993, Duffield et al. 1995, Lean et al. 1991, Lean et al. 1992, Drackley et al. 1992).

Em vacas leiteiras a cetose ocorre principalmente logo após o parto. Os principais sinais clínicos da cetose são: queda acentuada na produção de leite, perda de apetite principalmente de alimentos concentrados, alterações nas fezes e ocasionalmente sinais neurológicos (Duffield et al. 1995). Estes sintomas são evidentes permitindo que o produtor tome as providências necessárias.

A cetose também pode ocorrer sem que o animal apresente os sinais clínicos da doença, só podendo ser detectada pela quantificação dos níveis de CC no soro ou leite, forma essa denominada de cetose subclínica. Embora esta palavra "subclínica" seja considerada incorreta por alguns pesquisadores já que a doença pode ser diagnosticada por algum meio, este termo tem sido aceito e tradicionalmente utilizado pela grande maioria dos autores para definir esta condição em que há aumento excessivo nos níveis de CC circulantes sem a expressão dos sinais clínicos. Dados de pesquisa em vários países relatam 
a cetose subclínica como sendo de maior ocorrência, o que nos leva a concluir que esta seja a forma que causa maiores prejuízos à exploração leiteira.

$\mathrm{Na}$ maioria das vezes a cura da cetose ocorre espontaneamente, sem tratamento, pela redução natural na produção de leite ou aumento voluntário no consumo de MS, mas até que isso ocorra a produção total já terá sido afetada. Embora a prevenção seja a única maneira de evitar os prejuizos, alguns testes de campo também tem sido utilizados na tentativa de identificar precocemente o aparecimento da cetose através da presença de CC no leite e assim minimizar os prejuízos.

Considerando que o fator chave na susceptibilidade da vaca aos transtornos no metabolismo da energia é a prioridade metabólica dada à demanda por nutrientes pela glândula mamária, numa fase em que o apetite é limitado, para se prevenir estes transtornos se faz necessário conhecer os efeitos do início da lactação no metabolismo intermediário, controle do apetite e perda de condição corporal.

Dessa forma, entre as doenças da produção que afetam a saúde da vaca leiteira no início da lactação os transtornos no metabolismo da energia, que também pode ser definido como cetose, se incluem dentre os mais importantes pois interferem diretamente no pico de produção de leite, além de haver suspeitas que estejam relacionados com a redução da performance reprodutiva e aumento da incidência de doenças do periparto.

Nos países mais avançados tem havido grande interesse no estudo da cetose, principalmente para se conhecer os mecanismos bioquímicos pelos quais a deficiência de energia afeta adversamente a produtividade e assim possibilitar regular o balanço energético negativo que ocorre após o parto.

Em nosso país, de acordo com a atual tendência dos criadores em querer aumentar a produção de leite com menor custo possível, foi hipotetizado que esses transtornos no metabolismo da energia possam estar 
ocorrendo de maneira significativa em nosso meio e exercendo um impacto substancial na produção de leite nos rebanhos mais produtivos.

No Brasil poucos trabalhos foram desenvolvidos nesta área, principalmente utilizando análise quantitativa de $\mathrm{CC}$ e também relacionando cetose com condição corporal e outras doenças, o que pode ser observado pela modesta literatura nacional a esse respeito.

Dessa forma se justifica um estudo em nosso meio referente a esta enfermidade metabólica que pode se tornar futuramente uma das causas de prejuízo considerável na produtividade das fazendas que estão melhorando cada vez mais a capacidade produtiva de seus rebanhos.

Os objetivos deste trabalho foram:

a) determinar a incidência de animais que apresentam transtornos no metabolismo da energia, diagnosticados como cetose;

b) estudar o efeito da condição corporal ao parto sobre alguns parâmetros do metabolismo energético, produção de leite e incidência de doenças no início da lactação;

c) estudar o efeito da perda de peso nas oito primeiras semanas de lactação sobre alguns parâmetros do metabolismo energético, produção de leite e incidência de doenças no início da lactação;

d) estudar os níveis plasmáticos de BHBA nas oito primeiras semanas de lactação e sua correlação com vários parâmetros tais como: número de lactação, produção de leite, níveis de glicose plasmática, níveis de aspartato-aminotransferase plasmática (AST), presença de CC no leite, 
escore de condição corporal (ECC) ao parto, perda de ECC, perda de peso e doenças que ocorrem no período pós parto.

e) avaliar dois testes de campo aplicados ao leite para diagnosticar cetose subclínica e sua concordância com teste laboratorial.

Dessa forma poderá se obter dados para futuramente estimar a incidência de cetose em vacas leiteiras sob nossas condições e também adquirir experiência para estruturar futuras pesquisas nesta área. 


\section{REVISÃO DE LITERATURA}

\subsection{Introdução}

O suprimento energético aos tecidos corporais é feito continuamente através da oxidação de compostos de carbono. Entre todos os compostos de carbono apenas um número limitado pode ser oxidado a nível celular, sendo que o corpo provê aos tecidos um constante suprimento destes compostos através de um elaborado sistema de transporte e interconversão entre carboidratos, lipídios e proteínas. Quando este sistema falha, surgem os chamados transtornos no metabolismo da energia.

Segundo Herdt (1988), o final da gestação e início da lactação representa uma difícil demanda metabólica para a vaca leiteira, pois além do grande requerimento em energia há ainda necessidade de enormes quantidades de glicose propriamente dita para sustentar a síntese de lactose pela glândula mamária, e que as vacas de alta produção podem requerer para esta finalidade até $80 \%$ do suprimento total de glicose para o organismo.

Paradoxalmente ao aumento no requerimento de energia no final da gestação e no período pós-parto, a vaca experimenta uma dramática redução no consumo de MS imediatamente antes do parto (Bertics et al. 1992, Vazquez-Anon et al. 1994). Recentemente Santos (1996), estudando o efeito da condição corporal pré parto sobre a performance lactacional em dois grupos de vacas consideradas como sendo gordas (ECC $>4$ ), e magras ( $E C C<3,5$ ), encontrou uma redução no consumo de MS entre as últimas quatro semanas 
de gestação até o dia do parto, de $64 \%$ e $52 \%$ para os dois grupos respectivamente.

Devido ao aumento na demanda em energia sem o correspondente aumento na ingestão de alimentos, a maioria das vacas experimentam algum grau de deficiência energética, o que resulta em mobilização das reservas corporais (Duffield et al. 1995, Baird, 1982). A maioria das reservas corporais esta estocada na forma de lipídios no tecido adiposo, sendo que este é o principal tecido mobilizado durante o déficit energético (Komaragiri e Erdman, 1995. Bauman e Currie (1980), calcularam que as vacas com pico de produção acima de $35 \mathrm{~kg}$ (4\% FCM), mobilizam energia equivalente a $50 \mathrm{~kg}$ de lipídio ou $9 \mathrm{~kg}$ de leite por dia durante as primeiras 10 semanas de lactação.

A mobilização das reservas corporais aumentou drásticamente a infiltração de gordura no tecido hepático neste período (Vazquez-Anon et al. 1994, Studer et al. 1993), que associado ao déficit em glicose levou a um aumento na produção $\mathrm{CC}$. $\mathrm{O}$ aumento dos $\mathrm{CC}$ pode ser detectado no sangue, leite e urina e dependendo da sua magnitude leva a uma condição também conhecida como cetose (Lingaas e Tveit, 1992, Drackley et al. 1992, Baird, 1982, Hibbitt, 1979).

\subsection{Considerações sobre cetose de vacas leiteiras}

De acordo com Gustafsson et al. (1993), a cetose é um problema associado diretamente ao inadequado suprimento energético para vacas leiteiras de alta produção no inicio da lactação. Uma de suas características bioquímicas é o aumento dos níveis de CC circulantes, os sintomas são inespecíficos e se confundem facilmente com os de outras doenças comuns neste período, dificultando sua identificação. No entanto, uma redução no 
apetite e na produção de leite estão sempre presentes, e embora possam não ser percebidas, são suficientes para causar prejuízos. Duffield et al. (1995), definiu esta situacão onde haviam elevados níveis de CC circulantes sem expressão de sinais externos que pudessem distinguir a vaca cetótica das demais como sendo uma forma subclínica de ocorrência da doença.

A cetose foi descoberta no século passado e desde o início deste século tem sido objeto de estudo em vários países (Shaw, 1956; Pehrson, 1966). Há uma tendência em ocorrer principalmente em animais de alta produção e por isso esta condição é reconhecida como sendo de substancial significado econômico numa exploração leiteira (Littledike et al., 1981).

Inicialmente a cetose foi descrita como sendo somente uma desordem no metabolismo de carboidratos (Krebs, 1966). Embora na década de 80 muitos progressos tenham sido obtidos a respeito de sua patogenia (Baird, 1982, Kronfeld, 1982), os seus mecanismos ainda não foram totalmente elucidados. Recentes descobertas no metabolismo de ruminantes sugeriram que além de carboidratos e lipídios, vários outros fatores metabólicos e hormonais também exerçem um impacto substancial na origem da doença.

Em vários países de todo mundo tem havido grande interesse em estudar a incidência de cetose nos rebanhos leiteiros, devido aos prejuízos que ela pode causar direta ou indiretamente.

Duffield et al. (1995), em recente pesquisa envolvendo vacas de 93 rebanhos no Canadá encontraram uma incidência de $14,1 \%$ de animais apresentando níveis plasmáticos de BHBA maior ou igual a $1200 \mathrm{umol} / \mathrm{L}$, nos primeiros 60 dias pós-parto, sendo este valor equivalente a 10,4 mg/dl. Nesta pesquisa foram estudadas 1333 vacas com número variado de parições, sendo que a partir da quarta lactação a incidência foi significativamente maior que na primeira $(P<0.05)$. 
Andersson (1988), relatou que nos estudos de campo envolvendo grande número de animais tem sido difícil identificar as vacas subclinicamente ou clinicamente cetóticas, assim como tem sido difícil colheitar dados clínicos e amostras de sangue e leite simultâneamente. Isto significa que a maioria das investigações que descrevem a prevalência de hipercetonemia podem estar incluindo ambas as formas.

A prevalência da doença é quase sempre relatada para os primeiros dois meses de lactação, com uma taxa variando de 7 a $32 \%$ de acordo com vários fatores incluindo número de parições, semana de lactação, produção do rebanho e estação do ano (Andersson e Emanuelson, 1985, Kauppinen, 1983, Dohoo e Martin, 1984, Duffield et al. 1995), sendo que o pico ocorreu usualmente durante a quarta semana de lactação (Dohoo e Martin, 1984). Todavia nos últimos anos tem sido relatado uma incidência maior nas duas primeiras semanas após o parto, sugerindo que o aumento do estresse no início da lactação devido a uma maior produção de leite tem mudado o pico de ocorrência da doença em direção ao parto (Duffield et al., 1995; Santos, 1996).

Dohoo et al. (1983), relataram uma taxa de incidência de 9,6\% para cetose subclínica em vacas canadenses e Riemann et al. (1985), relataram que $15 \%$ de todas as vacas da Noruega receberam tratamento para cetose. No norte da Europa vários trabalhos indicam uma incidência em torno de 11,5\% para cetose subclínica (Lindströn et al., 1984). Na Dinamarca, Wiladsem et al. (1993), verificaram que a incidência de vacas com hipercetonemia variava de zero a $40 \%$ dependendo da estação do ano, da idade e do intervalo de partos, com alta prevalência nos meses frios e em vacas mais velhas.

Kauppinen (1983), analisando níveis de acetoacetato no leite encontrou uma prevalência de $13 \%$ e $34 \%$ para cetose clínica e subclínica respectivamente em vacas das raças holandesa e ayrshire no início da 
lactação. Quirós et al. (1993), relataram uma incidência de 7,6\% de cetose subclínica em 19 rebanhos leiteiros da Costa Rica. Uma alta incidência (24\%) foi verificada por Fatur et al. (1993), em rebanhos do sul da Europa. Incidência menor $(3,7 \%)$ foi encontrada em rebanhos do Texas (Jordan e Fourdraine, 1993).

No Brasil, Magalhães e Belém (1995), realizaram um estudo preliminar sobre a ocorrência de cetose subclínica em um rebanho leiteiro. Estes autores estudaram 22 vacas da raça holandesa nas 6 primeiras semanas pós-parto, utilizando o teste de Rothera descrito por Kaneko (1980), para identificar a presença de CC no leite e encontraram uma incidência de 18,8\% de casos positivos, com maior ocorrência na terceira semana de lactação. Todavia em estudo anterior Castillo e Castillo (1994), analisando a presença de acetona e acetoacetato no leite de vacas leiteiras no início da lactação utilizando o mesmo método não puderam encontrar nenhum caso positivo, alegando que o elevado consumo de alimentos concentrados pelas vacas utilizadas em seu estudo poderia ser a causa.

Pode-se concluir que há muitas variações a respeito da incidência de cetose em vários países. Isto pode ser explicado pelo uso de diferentes métodos de diagnóstico e critérios de definição que separa animais normais e com cetose, além da variação que pode existir entre rebanhos e áreas geográficas.

Atualmente nos Estados Unidos, Canadá e vários países da Europa a cetose ainda é alvo de vários pesquisadores, confirmando sua importância numa exploração leiteira.

\subsubsection{Efeitos da cetose na produção de leite}

O relacionamento entre cetose e produção de leite foi investigado em vários trabalhos. A secreção de leite foi fortemente dependente da 
disponibilidade de glicose para a glândula mamária formar lactose (Hove, 1978), e foi evidente que a dificuldade em fornecer glicose suficiente para elevadas produções de leite contribuiu para o desenvolvimento de hipercetonemia.

A cetose, principalmente a forma subclínica, se reveste de grande importância econômica por ocorrer justamente no período mais crítico da lactação, onde o menor transtorno pode levar a perdas significativas na produção total de leite (King, 1979).

Tem sido relatada correlação positiva entre $C C$ no sangue e produção de leite (Herdt et al. 1981, Kauppinen, 1983, Andersson e Emanuelson, 1985,) sugerindo que as vacas mais produtoras padecem mais facilmente de transtornos no metabolismo da energia.

Detileux et al. (1994), pesquisaram os efeitos da cetose na produção de leite e verificaram que as vacas cetóticas apresentavam uma depressão na curva de lactação quando comparadas com vacas não cetóticas, e que a perda na produção de leite foi de $44,3 \mathrm{~kg}$ para os 17 dias subsequentes ao diagnóstico da doença. Todavia, neste mesmo experimento os autores estimaram que a produção de leite em 305 dias para as vacas com cetose foi maior em 141,1 kg do que o grupo não cetótico, e concluíram que embora perdas de leite tenham ocorrido após a doença, as vacas com cetose produziram mais leite na lactação total do que aquelas não cetóticas e que a produção poderia ter sido maior se as mesmas não tivessem sido afetadas pela cetose.

Por outro lado também tem sido relatado correlação negativa entre concentração de CC no leite e produção de leite (Dohoo e Martin, 1984; Andersson e Emanuelson, 1985).

Andersson e Gustafsson (1990), analizando 4 categorias de animais de acordo com os seus níveis de acetona no leite verificaram que a produção 
de leite foi menor na categoria com alto nível de acetona. Foi demonstrado também em outro excelente trabalho de Gustafsson et al. (1993), que, estudando 38.624 lactações de 474 rebanhos na Suécia, encontraram que as curvas de lactação das vacas cetóticas tinham uma forma anormal, com um pico invertido no início da lactação. Estudos realizados na Finlandia por Miettinen et al. (1993), demonstraram uma associação entre baixos niveis de acetona no leite e alta produção de leite, e que redução na produção ocorria em vacas com cetose subclínica no início da lactação. Estes autores concluíram ainda que as vacas cetóticas poderiam não alcançar o potencial máximo naquela lactação.

Em nosso entendimento CC no sangue apresentam correlação positiva com produção no leite, no entanto, quando ultrapassam os limites fisioló-gicos eles causam efeito negativo. Quando estes limites são ultrapassados os CC aparecem no leite, logo os CC no leite tendem a apresentar somente correlação negativa com produção de leite. Dessa forma podemos concluir que pelo menos durante o período de ocorrência da doença há redução na produção de leite e que mesmo que os animais mais produtivos sejam os mais afetados, a produção total de leite destes animais pode também ser menor que a do rebanho dependendo da magnitude das perdas e duração da cetose.

Os efeitos da seleção para produção de leite sobre a ocorrência de cetose também tem sido estudados. Tveit et al. (1992), analisando os fatores relacionados à etiologia da cetose na Noruega concluíram que uma intensiva seleção para produção de leite como único critério, pode futuramente causar aumento na incidência de cetose. Pesquisadores da universidade de Minnesota (Jones et al., 1994), reuniram dados de 16 anos de acompanhamento e verificaram que havia aumento significativo nos gastos com cetose no grupo selecionado em relação ao grupo controle, sugerindo aumento na incidência 
da doença quando se melhorava a produção do rebanho. Todavia, Duffield et al. (1995), investigando 1333 vacas em rebanhos no Canadá compararam os resultados de sua pesquisa com os resultados de pesquisas anteriores naquele país e concluíram que, embora a produção dos rebanhos naquele país tenha aumentado nos últimos 10 anos em 29 pontos na média de classificação de rebanhos, a incidência média de animais apresentando níveis de BHBA maiores que $12,5 \mathrm{mg} / \mathrm{dl}$ mudou muito pouco. Isto sugere que o melhor manejo e alimentação pode, em algum grau, reduzir o estresse lactacional.

Muitos pesquisadores tem demonstrado através de seus trabalhos as perdas que ocorrem na produção de leite. Dohoo e Martin (1984), estudaram lactações de vacas com hipercetonemia e concluíram que a cetose subclínica reduziu a produção de leite com níveis leve a moderado de hipercetonemia em $4,4 \%$ e 6,05\% respectivamente. Também Lucey et al. (1986), demonstraram uma redução de cerca de $70 \mathrm{~kg}$ de leite nas duas semanas em que as vacas apresentaram níveis altos de $\mathrm{CC}$ circulantes. Também em seu trabalho, Detileux et al. (1994), verificaram que as vacas cetóticas apresentavam uma perda na produção de leite de de $44,3 \mathrm{~kg}$ para os 17 dias subsequentes ao diagnóstico da doença.

Gustafssonn et al. (1993), analisando a produção de leite de vários rebanhos na Suécia estimou uma perda de $328 \mathrm{~kg}$ de leite nos primeiros 200 dias de lactação para os animais com níveis de acetona no leite acima de 4.1 $\mathrm{mg} / \mathrm{dl}$. Recentemente Guard (1996), utilizando resultados de pesquisa e experiência de campo, fez um levantamento sobre os custos da cetose em vacas leiteiras. Neste estudo o autor concluiu que $1 \%$ dos casos terminaram em morte da vaca, em $5 \%$ dos casos as vacas foram descartadas e nos demais casos as vacas apresentaram uma perda de leite de aproximadamente $200 \mathrm{~kg}$ para aquela lactação. Resultados de pesquisas realizadas na França envolvendo 4123 vacas de 47 rebanhos também têm apontado correlação 
significativa entre cetose e descarte (Beaudeau et al., 1994). Também na Noruega, o "Annual Report of the Norwegian Cattle Disease Recording System" (1992), apontou no ano de 1991 a cetose e mastite como sendo responsáveis por $60 \%$ de todos gastos com serviços veterinários naquele país.

\subsubsection{Efeitos da cetose na performance reprodutiva}

Também uma importante maneira pela qual a cetose pode afetar a produtividade do rebanho é através da redução da fertilidade. A função reprodutiva é estreitamente relacionada com a deficiência de energia e às mudanças metábolicas e hormonais que ocorrem no pós-parto.

Desde a década de 70 vários pesquisadores tem observado que baixo consumo de energia prejudica a função reprodutiva em vacas leiteiras (Lamond, 1970; Olds e Thrift, 1979; Spalding, 1975). Altas concentrações de CC no sangue também foram relacionadas com redução na fertilidade (Benjaminsen, 1977, citado por Baird, 1982), o que sugere uma interferência da cetose na reprodução.

Vários trabalhos relataram uma dilatação do período de serviço em vacas com deficiência energética (Stevenson e Britt, 1979; Andersson, 1988; Butler e Smith, 1989; Staples e Thatcher,1990).

A seleção genética para altas produções de leite resultou em aumento nos níveis sanguíneos de hormônios lactogênicos além de reduzir a insulina. Estas alterações afetaram de algum modo a atividade ovariana (Nebel e McGilliard, 1993; Spicer et al. 1993; Spicer e Echternkamp, 1995). Um efeito negativo de altos níveis de CC sobre o hormônio liberador de gonadotropina $(\mathrm{GnRH})$, liberado pelo hipotálamo tem sido sugerido (Butler \& Smith, 1989). Isto explicaria um maior período de serviço nos animais com altas concentrações de CC circulantes. 
O ponto máximo de deficiência energética ocorre durante as duas primeiras semanas de lactação (Butler et al., 1982; Grummer, 1995), e a primeira ovulação geralmente ocorreu aproximadamente 10 dias após o nadir do balanço energético (Butler et al., 1982; Butler e Smith, 1989). Vacas que chegam ao parto excessivamente condicionadas podem ter sua performance reprodutiva comprometida devido ao longo período de balanço energético negativo a que estão sujeitas (Fergusson, 1991; Fergusson et al., 1994; Garnsworthy et al., 1987; Garnsworthy, 1988; Gearhart et al., 1990).

Na Suécia Anderson e Gustafsson (1990), analisando 15438 vacas em 471 rebanhos verificaram que as vacas com altos níveis de acetona no leite apresentavam maior freqüência de cistos ovarianos e maior período de serviço. Também na Suécia, Emanuelson et al. (1993), estudando vacas de 1692 rebanhos naquele país puderam confirmar estes resultados e verificaram que a cetose aumentava o risco de ocorrer disfunção ovulatória. Dohoo e Martin (1984), relataram que a cetose aumentava o risco de ocorrer infecções uterinas e cistos ovarianos e Kuzma et al. (1994), verificaram diminuição na eficácia do tratamento para ovários císticos. Andersson e Emanuelson (1985), observaram que rebanhos com alta incidência de cetose subclínica tinham estes problemas reprodutivos.

\subsubsection{Relação com outras doenças}

Vários estudos epidemiológicos foram realizados para se estabelecer um relacionamento entre as doenças comuns do periparto e cetose (Markusfeld, 1985; Bendixen et al., 1987; Erb e Grohn, 1988; Grohn et al., 1989). Alguns transtornos à saúde da vaca leiteira puderam ser identificados como retenção de placenta (Curtis et al., 1985), obesidade (Fronk et al., 1980) e mastite (Ardersson, 1993). Dohoo e Martin (1984), relataram que as 
vacas com cetose tinham alto risco de desenvolver deslocamento de abomaso. Outras doenças como reticuloperitonite traumática, infecções uterinas e mastites também tem sido associadas.

Complementando estes resultados, Bendixen et al. (1987) constataram que paresia da parturiente também aumentava o risco de cetose, e nos trabalhos conduzidos por Grohn et al. (1989), diferentes problemas de casco também estavam asociados à doença. No Chile, Wittwer et al. (1993), analisaram os níveis plasmáticos de BHBA em 76 vacas com síndrome da vaca deitada. Neste trabalho os autores verificaram que, embora a causa principal da síndrome era paresia da parturiente, a cetose estava associada em $3 \%$ dos casos. Entretanto, para estes trabalhos concluímos que o aumento dos níveis de CC circulantes esteja ocorrendo principalmente de forma secundária devido à dificuldade do animal em se alimentar e podem não estar caracterizando devidamente a cetose de vacas leiteiras no pós-parto.

Mastite tem sido utilizada como exemplo de doença que tem seu risco aumentado com o surgimento da cetose (Baird, 1982, Emery et al., 1968; Littledicke et al., 1981). Anderson (1993), estudando rebanhos na Alemanha encontrou que esse risco poderia aumentar até 5 vezes em vacas com cetose e concluíram ainda que o risco de cetose era 3 vezes maior em vacas com paresia da parturiente. Resultados de pesquisas conduzidas na Universidade de Cornell puderam confirmar estes reultados. Nestes trabalhos, Oltenaco et al. (1994), verificaram ainda que vacas com mastite clínica produziram menos $260 \mathrm{~kg}$ de leite e tinham 2,8 vezes mais chances de serem descartadas. Por outro lado Emanuelson et al. (1993), analisando $18110 \mathrm{em}$ 924 rebanhos na Suécia verificaram que o risco de mastite foi influenciado somente por retençao de placenta, mas que a cetose aumentava falhas na ovulação. 
Muitas pesquisas tem sido conduzidas na tentativa de identificar os mecanismos através dos quais os CC possam influenciar a saúde geral do organismo. Um dos aspectos que tem recebido grande atenção, é como as mudanças bioquímicas que ocorrem no sangue poderiam influenciar a capacidade funcional das células do sistema imune, levando a uma diminuição da resistência às doenças em vacas com cetose.

Os resultados obtidos nestas pesquisas tem sido conflitantes. Vários autores sugeriram que o aumento nas concentrações de CC poderiam reduzir a atividade dos linfócitos-T e dessa forma tornava as vacas mais susceptíveis às doenças infecciosas durante a cetose clínica ou subclínica (Baird, 1982; Littledicke et al., 1981; Targowski e Klucínski, 1983; Targowski et al., 1985).

Targowski e Klucínski (1983), verificaram que linfócitos-T periféricos de bezerros com cetonemia induzida exibiram redução in vitro na sintese de DNA induzido por mitogênico em relação ao grupo controle, e que estes bezerros apresentaram sinais clínicos de problemas respiratórios, sugerindo que o sistema imune estaria comprometido.

Klucinski et al. (1988a), estudaram in vitro o efeito do aumento nas concentrações de BHBA, acetoacetato e acetona na atividade in vitro de linfócitos- $T$ isolados de leite e sangue periférico de vacas saudáveis. Os resultados destas pesquisas indicaram que pelo menos BHBA e acetoacetato prejudicaram a atividade destes linfócitos, os quais são de importância crucial na imunidade da glândula mamaréa. Complementando os resultados acima estes mesmos autores (Klucinski et al. (1988b), verificaram em outra pesquisa que os CC inibiam significativamente a atividade fagocítica de macrófagos e polimorfonucleares isolados de amostras de leite. Este autores sugeriram então que esta poderia ser uma das razões para a alta freqüência de mastite observada em vacas durante a cetose. 
Pesquisas realizadas na Inglaterra por Gregory et al. (1993), utilizando culturas de celulas- $T$ de seres humanos para verificar o efeito de BHBA no sistema imune de pacientes diabéticos, permitiu a esses autores concluir que em condições extremas de cetoacidose a atividade das celulas- $T$ poderiam estar reduzidas e poderia ser uma das causas da predisposição destes pacientes a infecçōes fúngicas.

Também estudos realizados na Alemanha por Kandefer et al. (1992), avaliaram a resposta do sistema imune de leucócitos em vacas lactantes com cetose e verificaram uma baixa atividade de interferom gama produzido por estas vacas em relação ao grupo de vacas saudáveis.

Kremer et al. (1993), avaliou a severidade de mastite experimental por $E$. coli em vacas cetonêmicas e saudáveis, e verificou que nas vacas com cetose, a mastite foi mais severa e negativamente relacionada com a quimiotaxia de leucócitos polimorfonucleares avaliados previamente in vitro.

Por outro lado, Franklin et al. (1991), através de estudos in vitro, apresentaram que $\mathrm{CC}$ em concentrações semelhantes à de vacas cetóticas não tiveram efeito na síntese de DNA por linfócitos-T. Também Nonneck et al. (1992), avaliaram os efeitos, individual e combinados de CC e glicose sobre a produção de $\operatorname{lgM}$ in vitro por linfócitos colheitados de novilhas holandesas previamente sensibilizadas, e concluíram que a secreção de IgM não foi afetada ou até moderadamente estimulada na presença de CC em níveis correspondentes aos que ocorrem na cetose de vacas leiteiras.

Dessa forma, podemos concluir que o estado hipercetonêmico parece realmente estar relacionado com a maior incidência de algumas doenças na vaca leiteira no pós-parto, contudo os resultados de pesquisas realizadas na tentativa de elucidar os mecanismos pelos quais isso ocorre ainda não são bastante concordantes. Uma das causas deste conflito pode ser 
as variações na metodologia utilizada e também na dificuldade em analisar as respostas obtidas em experimentos realizados in vitro.

\subsection{Avaliação de transtornos no metabolismo energético da vaca leiteira no pós-parto}

Segundo Andersson (1988), transtornos no metabolismo da energia em vacas leiteiras podem ser identificados analisando-se os níveis plasmáticos de glicose, níveis plasmáticos de AGNE e os níveis de CC no sangue, leite e urina.

Glicose plasmática tem sido utilizada extensamente para avaliar o perfil do metabolismo da energia como indicador do estado energético (Payne, 1987), e tem sido correlacionada negativamente com níveis de CC circulantes (Herdt, 1988). Todavia, Lindsay (1993), tem sugerido que a glicose plasmática pode não ser um bom indicador do estado energético devido à grande regulação homeostática a que está sujeita.

A concentração de CC plasmático aumenta no início do período pósparto e reflete o aporte de triglicerídeos hepáticos (Grummer, 1995). A semana de lactação em que ocorre o pico de BHBA plasmático pode variar entre rebanhos porém ocorre geralmente no primeiro mês após o parto. Nos últimos anos parece ter havido uma tendência em ocorrer mais próximo do parto, na 2. e 3- semanas de lactação (Bertics et al., 1992; Studer et al., 1993; Vazquez-Anon et al., 1994). Santos (1996), concluiu que isto tenha sido provavelmente devido ao aumento na demanda energética para síntese de leite sem haver proporcional aumento no consumo de alimento. Isto vem a confirmar a importância dos CC para avaliar o estado energético da vaca de leite. 
Mais recentemente, Duffield et al. (1995), estudando 1333 vacas em 93 rebanhos no Canadá relataram o pico de BHBA plasmático ocorrendo nas duas primeiras semanas pós-parto. Por outro lado Quirós et al. (1993), estudando 248 vacas holandesas em dezenove rebanhos na Costa Rica encontraram maiores concentrações de BHBA séricos e baixos níveis de glicose plasmática somente na quinta semana de lactação. Os próprios autores explicaram que isto pode ser devido à menor média de produção de leite dos rebanhos amostrados em seu estudo.

Em muitas pesquisas, BHBA tem sido um dos $\mathrm{CC}$ mais freqëntemente quantificados no plasma para monitorar o estado energético e identificar vacas que estejam com cetose subclínica (Andersson, 1988). Estudos realizados em Minessota revelaram que BHBA do sangue foi uma variável bastante acurada para detectar cetose (Herdt, 1981).

Whitaker (1983), tem relatado em sua experiência de campo que sempre que um grupo de vacas no início da lactação apresentava níveis de BHBA acima de $10.0 \mathrm{mg} / \mathrm{dl}$, significava que elas estavam em um estado de deficiência energética. Todavia o nível limiar que separa animais normais de animais cetóticos ainda é muito controverso.

Segundo Lindsay (1993), uma ligeira acetonemia em ruminantes é considerada normal, e origina da produção de corpos cetônicos no trato gastrintestinal. De acordo com este autor níveis de $6,25 \mathrm{mg} / \mathrm{dl}$ de BHBA para vacas alimentadas podem ser considerados normais, mas em casos de transtornos metabólicos estes valores podem aumentar 5 a 10 vezes.

Inicialmente Shultz et al. (1959), sugeriram que $6,3 \mathrm{mg} / \mathrm{dl}$ de BHBA poderiam indicar hipercetonemia em vacas. Posteriormente, a utilização do método enzimático descrito por Williamson et al. (1962), muito contribuiu para uma melhor aproximação dos valores normais de $\mathrm{CC}$ em vacas de leite. Provavelmente baseados nos resultados encontrados com o uso deste método 
Blood et al. (1986), tem sugerido para vacas em lactação valores de até $<10$ $\mathrm{mg} / \mathrm{dl}$ como sendo normais. Nielen et al. (1994), tem adotado um valor de $10,4 \mathrm{mg} / \mathrm{dl}$ como sendo o limiar entre animais normais e com cetose. Estes mesmos niveis tem sido utilizados em recentes pesquisas para identificar a incidência de cetose subclínica em vacas leiteiras no Canadá (Duffield et al., 1995).

Acetona e acetoacetato no leite também foram investigados como auxiliar na avaliação de transtornos energéticos em ruminantes (Andersson, 1988). Hagert (1991), avaliou os níveis de acetona no leite como método de controle do estado energético do rebanho até o pico de lactação, e concluiu que a acetona é um bom indicador de dirtúrbios metabólicos nesta fase.

Um teste semiquantitativo, também chamado de Rothera, baseado na reação da acetona e acetoacetato com o nitroprussiato de sódio em meio alcalino, no caso o carbonato de sódio, foi descrito inicialmente para identificar vacas cetóticas a nível de campo (Emery et al., 1968; Shultz et al., 1959).

Este método tem sido utilizado para pesquisar, a nível de campo, a presença de CC na urina (Magalhães e Belem, 1995, Castillo, 1994, Quirós et al. 1993). Também na Índia, estudos realizados por Ziauddin et al. (1992), utilizando o teste de Rothera na urina demonstraram que em 224 vacas $(30,3 \%)$ de 757 apresentavam cetonúria. Na Hungria, muitas pesquisas com cetose de vacas leiteiras são conduzidas baseadas somente na cetonúria apresentada pelas vacas (Kegl e Gaal, 1992; Kegl, 1992).

A leitura dos resultados com nitroprussiato é feita de maneira subjetiva, de acordo com a intensidade da cor, e apresentados na forma de cruzes $(+++)$. Markusfeld et al. (1984), e Shultz et al. (1959), propuseram a seguinte leitura para o teste aplicado na urina e leite respectivamente. 


\section{Reacão com nitroprussiato em meio alcalino}

$\begin{array}{llcc}\text { Classificação } & \text { Cor } & \text { Urina }(\mathrm{mmol} / \mathrm{l}) & \text { Leite }(\mathrm{mg} / \mathrm{dl}) \\ \text { Negativo }(-) & \text { não muda } & <0,5 & <4,0 \\ \text { Leve }(+) & \text { rosada } & 0,5-1,5 & 4,2 \\ \text { Moderado }(++) & \text { rosa intenso } & 3,9-7,8 & 5,0 \\ \text { Severo }(+++) & \text { violeta-púrpura } & 8,0-15,6 & >5,5\end{array}$

Nielen et al. (1994), realizaram um estudo com o objetivo de avaliar a sensibilidade e especificidade deste método. Estes autores utilizaram amostras de leite e urina de 185 vacas durante os primeiros 60 dias pós-parto e compararam com os resultados obtidos através da mensuração dos níveis plasmáticos de BHBA utilizados para definir cetose subclínica. A sensibilidade e a especificidade do método, tanto no leite quanto na urina foram diferentes. No leite a sensibilidade foi de $90 \%$ e a especificidade de $96 \%$, porém na urina, embora a sensibilidade tenha sido de $100 \%$, a especificidade foi de apenas $67 \%$.

Todavia, quando se utiliza a reação com nitroprussiato em amostras de leite, a sensibilidade pode ser menor que aquela encontrada pelos autores acima se a incidência de cetose for grande na fase de colostro, devido à dificuldade de definir resultados realmente positivos. Duffield et al. (1995), relatou a sensibilidade deste método como sendo somente de $73 \%$ e com especificidade de $98 \%$ e, de acordo com este autor isto poderia subestimar a verdadeira incidênciade cetose.

Baseados nestes resultados podemos sugerir que as pesquisas utilizando somente urina podem ser falhas devido ao grande número de casos falso positivos. Isto pode ser explicado pelo fato de os CC serem facilmente eliminados através da urina, a uma concentração de até várias vezes maior que 
a do sangue, o que leva a uma baixa correlação com uso de plasma ou leite para diagnosticar a cetose. Também podemos concluir que devido a eficiência do método e principalmente pela facilidade na obtenção de amostras, a análise de leite pode ser preferida em relação à urina.

Outro método para quantificar acetona e acetoacetato no leite foi desenvolvido na Suécia utilisando a técnica de análise de fluxo contínuo (Marstorp et al., 1983), e posteriormente modificada por Andersson e Emanuelson, (1985). Este método tem sido relatado como sendo de baixo custo por amostra, simples e seguro, com posibilidade de automatização, podendo analisar até 100 amostras por hora (Andersson, 1988).

$\mathrm{Na}$ Europa o uso deste método tem sido de grande auxílio para controlar a cetose a nível de rebanho em vários países, através da análise de amostras de leite obtidas em tanques, no entanto o período ideal de amostragem vai depender da incidência de animais positivos no rebanho. Gustafsson et al. (1993), utilizaram este método em amostragem mensal para pesquisar a concentração de acetona no leite em 3.8624 lactações de vários rebanhos na Suécia e adotaram o nível de $0,40 \mathrm{mmol} / \mathrm{L}$, equivalente a 4,1 $\mathrm{mg} / \mathrm{dl}$, como o limiar que separa animais normais e com hipercetonemia. Estes autores consideraram que amostras mensais podem subestimar a incidência real de cetose.

Wiladsen et al. (1993), utilizaram amostras de leite colhidas mensalmente no tanque para estudar a incidência de vacas com hipercetonemia na Dinamarca, porém concluíram que somente em rebanhos com incidência excepcionalmente alta de cetose a amostragem mensal de leite seria adequada. Nemec et al. (1993), trabalharam com amostragem semanal e concluíram em seu experimento que este período seria ideal para detectar rebanhos com vacas hipercetonêmicas. 
Níveis plasmáticos de AGNE também tem sido pesquisados como forma de avaliar o metabolismo energético de vacas no pós-parto. A alta demanda energética que ocorre em vacas no início da lactação sem o devido aumento no consumo de MS leva a uma intensa mobilização de reservas corporais. O tecido mobilizado foi principalmente gordura corporal (Komaragiri e Erdman, 1995), o que resultou em altos níveis de AGNE circulantes. A infiltração de gordura no tecido hepático é então drásticamente aumentada neste período (Vazquez-Anon et al., 1994; Studer et al., 1993).

Vacas que estão muito gordas mobilizam mais gordura no periparto e apresentam altos niveis de AGNE (Treacher et al., 1986; Reid et al., 1986; Pedron et al., 1993), e uma relação inversa entre consumo de alimento e AGNE no plasma tem sido demonstradas em vários estudos (Bertics et al., 1992; Studer et al., 1993; Grummer, 1993; Vazquez-Anon et al., 1994).

Aspartato-aminotransferase (AST), também tem sido utilizada como indicador do aumento da atividade gluconeogênica (Zurek et al., 1994). Roberts e Reid (1986), propuseram que níveis plasmáticos de AST em conjunto com AGNE e níveis de glicose podem ser utilizados para predizer extensa infiltração de gordura no fígado. Em nosso entendimento há necessidade de confrontar esta hipótese com resultados de biópsia hepática.

Nos últimos anos tem merecido grande interesse dos pesquisadores o estudo do escore de condição corporal (ECC) ao parto e sua perda no início da lactação. O ECC é uma maneira subjetiva de avaliar as reservas energéticas da vaca e é baseado na observação visual e palpação de áreas específicas para avaliar os depósitos de tecido adiposo e massa muscular.

Patton et al. (1988), tem sugerido que as vacas que parindo sem uma adequada reserva corporal podem ser mais propensas à doenças infecciosas, transtornos metabólicos, baixa eficiência reprodutiva e redução na produção de leite, enquanto vacas excessivamente gordas estão mais 
predisposta a dificuldades de parto, síndrome da vaca gorda e às vezes morte. Edmolson et al. (1989), sugeriram que as vacas com alta condição corporal (4 $-4,25)$, são mais propensas à cetose devido ao fato de que elas tem menor consumo logo após o parto e mobilizam mais reservas corporais.

Segundo Fergusson et al. (1994), tanto as vacas muito gordas como muito magras correm o risco e ter problemas metabólicos e doenças, redução na produção de leite e na taxa de concepção e dificuldade em parir. Estes mesmos autores sugeriram os seguintes valores para o ECC nos diferentes estágios de produção de novilhas e vacas.

Estágio da lactacão

Período seco

Parto

Início da lactação

Meio da lactação

Fim da lactação

Novilhas em crescimento

Novilhas ao parto
ECC ideal

3,50

3,50

3,00

3,25

3,50

3,00

3,50

\section{Intervalo sugerido}

$3,25-3,75$

$3,25-3,75$

$2,50-3,25$

$2,75-3,25$

$3,00-3,50$

$2,75-3,25$

$3,25-3,75$

Domeck et al., (1995), estudando a relação entre ECC e gordura subcutânea em vacas, determinada pela técnica de ultrassonografia, concluíram que o ECC refletiu adequadamente as reservas de gordura neste tecido.

O ECC varia de acordo com o método adotado, porém valores mais altos sempre indicam vacas mais gordas. Wildman et al. (1982), e Edmolson et al. (1989), propuseram uma escala de 1 a 5 com intervalo de 0.25 pontos para medir o ECC, sendo este um método bastante utilizado nos Estados Unidos. 
As mudanças no ECC entre o final da gestação, parto e início da lactação tem sido responsabilizadas por baixar a performance pós-parto e aumentar a incidência de transtornos metabólicos em vacas de leite (Wildman et al., 1982; Rueg et al., 1992). Nos Estados Unidos, vacas que pariram com ECC próximo de 4,0 foram consideradas propensas a terem mais problemas de mastite, doenças metabólicas e problemas reprodutivos (Curtis et al., 1985; Patton et al., 1988; Fergusson et el., 1994). Todavia pesquisas na Inglaterra (Garnsworthy et al., 1987), não puderam associar alta condição corporal ao parto e incidência de doenças metabólicas. Um experimento foi conduzido na Universidade de Cornell com objetivo de estudar o efeito de diferentes ECC ao parto sobre a performance pós-parto, porém os autores não observaram nenhuma diferença significativa com relação à incidência de transtornos no metabolismo (Butler e Smith, 1989).

No Canadá Ruegg e Milton, (1995), conduziram um estudo utilizando 429 vacas com objetivo de determinar o relacionamento entre ECC e perda de ECC com produção de leite, performance reprodutiva e incidência de doenças. Neste estudo os autores concluíram que não houve perda de condição corporal significativa entre os animais que tiveram doença metabólica e animais sadios e que o ECC ao parto não influenciou a performance da lactação. Isto concorda com os resultados apresentados por Gearhart et al. (1990), que também relataram não haver diferença significativa entre o ECC ao parto e o risco de doenças metabólicas.

Recentemente na Universidade do Arizona, Santos, (1996), conduziu um experimento para avaliar o efeito de ECC ao parto sobre a performance lactacional. No seu estudo este autor não observou nenhuma diferença na produção ou composição do leite entre dois grupos de vacas considerados gorda e magra. Também a incidência de doenças metabólicas, problemas reprodutivos e performance reprodutiva não foram afetadas. 
Entretanto, observou que as vacas mais gordas perderam mais ECC e tinham niveis de BHBA mais altos.

Em conclusão, ainda há controvérsias a respeito do efeito do ECC ao parto sobre a performance lactacional. A obtenção de diferentes resultados em torno dos trabalhos com ECC podem ser explicados pela variação dos critérios adotados para aproximação do ECC, assim como as diferenças entre os rebanhos em termos de manejo, alimentação e produção. De certa forma a avaliação do ECC no pós-parto pode ser útil como estratégia para evitar que as vacas venham a parir muito gordas ou muito magras (Fergusson, 1991). 


\section{3 - MATERIAL E MÉTODOS}

Cento e dezoito vacas holandesas, que pariram entre cinco de fevereiro a 24 de junho de 1996, foram estudadas com relação à ordem de lactações, produção de leite, teor de gordura e presença de CC no leite, peso e condição corporal, níveis plasmáticos de BHBA, glicose e AST, durante as oito primeiras semanas de lactação. Também foram observadas as doenças que ocorreram neste período.

Os animais utilizados pertenciam a um rebanho comercial situado a noroeste do estado de São Paulo. Durante o período experimental o rebanho contava, em média, com 350 vacas em lactação, produzindo $8.011 \mathrm{~kg}$. de leite/dia.

As instalações eram do tipo "free-stall" e os animais permaneciam agrupados em lotes de acordo com a produção de leite. As vacas eram ordenhadas três vezes ao dia $(4,12$ e 20 horas), e recebiam alimentação completa com 3 refeições diárias (4, 10 e 16 horas), em quantidade suficiente para exceder em torno de $5 \%$ do consumo voluntário, atendendo ou excedendo os requerimentos para vacas em lactação (NRC 1989), em proteína bruta, nutrientes digestíveis totais, vitaminas e minerais (Tabelas 1 e 2 do anexo).

Durante o período experimental, que compreendeu do parto até a $8^{a}$ semana de lactação, as vacas foram submetidas semanalmente às seguintes avaliações e colheita de amostras: 
a) pesagem individual da produção de leite a cada semana;

b) avaliação da condição corporal utilizando uma escala de 1 (magra), a 5 (gorda), com intervalo de 0,25 pontos, de acordo com o critério proposto por Ferguson et al. (1994);

c) colheita de amostra de sangue, à vácuo, em recipiente contendo antiglicolítico (heparina), e anticoagulante (fluoreto de sódio), para determinação de BHBA, glicose e AST. Estas amostras foram colhidas sempre no mesmo horário (de 9 às 10 horas da manhâ), em relação ao manejo e alimentação dos animais na tentativa de minimizar o efeito das variações diurnas que ocorrem nos níveis plasmáticos destas substâncias. As amostras foram mantidas em gelo até o término da colheita (menos de 1 hora), e então foram centrifugadas a $1100 \times$ g. O plasma obtido foi dividido em alíquotas e armazenadas a $-20^{\circ} \mathrm{C}$ em tubos criogênicos de 1,5 $\mathrm{ml}$ para posterior análise;

d) colheita de amostra de leite para determinação de gordura, e determinação semiquantitativa de acetona e acetoacetato através dos testes de campo;

e) avaliação do estado geral de saúde utilizando os métodos semiológicos rotineiros, dando atenção especial às enfermidades de maior ocorrência neste período como distocia, retenção das membranas fetais, infecção uterina, hipocalcemia, problemas de pé ou casco, mastite e cistos ovarianos;

f) avaliação do sistema reprodutivo, a partir da $3^{a}$ semana de lactação, com atenção especial para a atividade ovariana.

As vacas foram pesadas logo após o parto, na quarta e na oitava semana de lactação para verificação da perda real de peso. 
Amostras do alimento foram colhidas semanalmente e armazenadas a $-20^{\circ} \mathrm{C}$ para posterior análise bromatológica.

\subsection{Análises de campo}

Imediatamente após a colheita, o leite foi submetido à pesquisa de acetona e acetoacetato, utilizando o reagente para leite ketoCheck (Great States Animal Health, Inc, P.O. BOX 8111, St. Joseph, MO 64508, USA), e também utilizando o teste modificado de Ross' (Rothera pó), descrito por Kaneko (1980), que se baseiam na intensidade da coloração púrpura formada pela reação destes $\mathrm{CC}$ do leite com o nitroprussiato de sódio em meio alcalino, no caso o carbonato de sódio. Os resultados foram observados em termos de uma, duas ou três cruzes e transformados posteriormente em números 1,2 e 3 respectivamente.

\subsection{Análises de laboratório}

Após o término do período experimental as amostras de plasma, leite e alimento foram submetidas às análises de laboratório.

A porcentagem de gordura do leite foi obtida utilizando-se o método de separação por ácido sulfúrico.

Os niveis plasmáticos de BHBA foram obtidos utilizando o Kit $n^{\circ}$ 310-A (Sigma Diagnostics, P.O. BOX 14508, St. Louis, MO 63178, USA), que se baseia no método enzimático descrito por Willianson (1962). Os resultados foram dados em miligramas por decilitro (mg/dl).

A glicose foi quantificada enzimaticamente utilizando o Kit No 315100 (Sigma Diagnostics, P.O BOX 14508, St. Louis, MO 63178, USA), que segue o método da glicose oxidase descrito por Tietz (1982), adaptado para 
ser usado em placas de microtítulo e posterior leitura em aparelho do tipo "Elisa Reader", que apresenta os resultados em mg/dl.

A enzima hepática aspartato-aminotransferase foi determinada utilizando o Kit AST Reagent - IFCC (Ciba Corning Diagnóstics Corp., Oberlin, Ohio, 44074, USA), que se baseia na metodologia da "International Federation of Clinical Chemistry" (1975), e apresenta os resultados em Unidades Internacionais (UI).

As amostras de ração completa foram compostas em 10 amostras, representando cada duas semanas consecutivas do experimento e analizadas para se obter MS, proteína bruta, fibra em detergente ácido, fibra em detergente neutro, extrato etéreo, estrativo não nitrogenado e cinzas.

\subsection{Variáveis}

As variaveis estudadas foram:

produção de leite;

teor de gordura no leite;

condição corporal ao parto;

variação na condição corporal após o parto;

peso corporal ao parto;

variação no peso após o parto;

níveis plasmáticos de $\mathrm{BHBA}$;

níveis plasmáticos de glicose;

níveis plasmáticos de AST;

presença de CC no leite. 


\subsection{Análise estatística}

Os dados obtidos foram analisados de acordo com o esquema "Splitplot", onde as vacas foram divididas em dois grupos de acordo com os níveis de BHBA (com cetose e saudável), efeito este considerado como parcela ou "Whole-plot", e as medidas repetidas na mesma vaca (semanas), como subparcelas.

A análise foi feita usando O PROC MIXED (Latour, 1994), considerando efeitos fixos de grupo, semana e interação grupo x semana.

Os efeitos de vacas dentro dos grupos foram considerados como aleatórios.

As médias ajustadas (LSMeans), dos efeitos fixos foram comparadas através da diferença mínima significativa (LSD), obtida pelo teste " $\underline{\text { ". }}$ "

A incidência de doenças nos grupos foram comparadas através do teste de Qui-Quadrado $\left(x^{2}\right)$.

As vacas também foram divididas de acordo com o ECC ao parto (gorda $\mathrm{x}$ magra), e com a perda de peso (emagreceu mais $\mathrm{x}$ emagreceu menos), e aplicado o mesmo procedimento acima. 


\section{RESULTADOS E DISCUSSÃO}

\subsection{Incidência de cetose}

Um total de cento e dezoito vacas foram utilizadas para avaliar a incidência de cetose.

Cetose foi definida nas vacas que apresentavam concentrações plasmáticas de BHBA acima de $10 \mathrm{mg} / \mathrm{dl}$. Embora o limiar que separa animais sadios e com cetose ainda é controverso este valor é semelhante ao adotado na maioria das pesquisas (Whitaker, 1983; Blood et al., 1986; Nielen et al., 1994; Duffield, 1995; Santos, 1996), e está acima do nível de 6,25 mg/dl considerado normal para vacas bem alimentadas (Lindsay, 1993).

Utilizando este limite, a cetose foi observada em 16 animais, representando $13,56 \%$ da amostra, sendo que apenas 1 caso $(0,84 \%)$ evoluiu para a forma clínica. Comparando com outros trabalhos no Brasil, Magalhães e Belém, (1995), encontraram incidência de $18,18 \%$, e Castillo (1994), não encontrou um caso sequer em seus estudos. Isto pode ser devido as diferenças entre os rebanhos utilizados com relação ao manejo, alimentação e nivel de produção das vacas. Uma grande diferença na prevalência de cetose entre rebanhos tem sido reportada por outros autores (Herdt et al., 1981, Dohoo e Martin, 1984, Andersonn e Emanuelson, 1985), sendo que Tveit et al. (1992), concluíram em seu trabalho que fatores ambientais contribuem significativamente para estas diferenças. 
Quando este período foi dividido em semanas, o pico de incidência ocorreu na primeira e segunda semana de lactação (Tabela 3 do anexo). Pesquisa anteriores relataram o pico de ocorrência na quarta semana (Andersonn e Emanuelson, 1985; Dohoo e Martin, 1984; Kauppinen, 1983), resultados semelhantes em estudos com BHBA foram apresentados por outros pesquisadores que afirmaram ser o pico de BHBA mais alto próximo ao parto, na $2^{\mathrm{a}}$ e $3^{\mathrm{a}}$ semanas de lactação (Bertics et al., 1992; Studer et al., 1993; Vazques-Anon et al., 1994; Santos, 1996). Dufield (1995), também encontrou incidência maior de cetose na $1^{\text {a }}$ e $2^{\mathrm{a}}$ semanas, e sugeriu que o estresse causado pela maior produção de leite devido ao aumento no potencial genético dos rebanhos poderia estar antecipando o pico de incidência para mais próximo do parto.

0 efeito do número de parições também foi avaliado (Tabela 4 do anexol. Houve uma tendência em aumentar o número de casos com o aumento no número de partos, concordando com trabalhos anteriores (Shaw, 1956; Dohoo e Martin, 1984; Kauppinen, 1983; Lindstron et al., 1984; Bendixen et al., 1987; Grohn et al., 1989), sendo que não houve nenhum caso nos animais de primeira lactação.

A avaliação dos testes de campo aplicado ao leite para identificar animais com altos niveis de corpos cetônicos mostrou que não houve diferença entre os resultados do KetoCheck e do teste de Ross, porém o teste de Ross pode ser de difícil leitura quando os reagentes utilizados no seu preparo não forem bastante puros. A sensibilidade dos testes quando comparadas com resultados laboratoriais foi de $76 \%$, concordando com os resultados de Duffield et al. (1995) e Quirós et al. (1993). Todavia nesta pesquisa observouse dificuldade em analisar amostras de leite que tenham resíduos de colostro. Isto pode ser um problema importante se realmente for confirmada uma grande prevalência de cetose na primeira semana de lactação, apoiada em resultados de pesquisas. 


\subsection{Avaliação do efeito de BHBA}

Para avaliar o efeito de BHBA na performance lactacional as vacas foram divididas em dois grupos, G. cetose e G. saudável, de acordo com os níveis de BHBA em uma dada semana. Foi chamado de G. cetose aquele em que os animais apresentaram BHBA plasmático acima de $10 \mathrm{mg} / \mathrm{dl}$ em pelo menos uma semana do período experimental, e, G. saudável aquele onde este valor ficou abaixo de $7 \mathrm{mg} / \mathrm{dl}$. 0 objetivo desta análise foi verificar o efeito destes 2 níveis de BHBA sobre a produção de leite e teor de gordura no leite, níveis plasmáticos de glicose e AST. Estes níveis de BHBA foram diferentes entre si $(P<0)$.

Os resultados mostraram que para todo o período experimental (Tabela 5 do anexo), não houve diferença significativa nos níveis plasmáticos de glicose e AST, assim como no teor de gordura no leite para os dois grupos. Entretanto, observou-se que a produção de leite foi menor $(P<0,058)$, no grupo cetose.

Analisando os resultados em cada semana separadamente (Tabela 6 do anexo), várias observações podem ser feitas.

O grupo cetose produziu mais leite na primeira semana e no entanto passou a produzir menos a partir da segunda semana, inclusive estatísticamente diferente na $3_{-}^{\mathrm{a}}, 4_{-}^{\mathrm{a}}, 6_{-}^{\mathrm{a}}, 7_{-}^{\mathrm{a}}$ e $8_{-}^{\mathrm{a}}$ semanas $(P<0,014 ; P<$ 0,030; $\mathrm{P}<0,0180 ; \mathrm{P}<0,047$ e $\mathrm{P}<0,037$, respectivamente), concordando com resultados encontrados por Drackley et al. (1992). Esta inversão na produção média de leite dos dois grupos ocorreu justamente na semana em que o nivel médio de BHBA foi máximo sugerindo que $\mathrm{CC}$ tenham influenciado negativamente a curva de produção. A hipercetonemia pode exercer um efeito "feedback" negativo no aporte de glicose para a glândula mamária, como foi observado em ratos (Robinson e Willianson, 1977), e segundo Andersson 
(1988), um mecanismo correspondente pode ser concebível em vacas. Sob este ponto de vista pode ser que os efeitos hormonais para promover a síntese de leite no início da lactação sejam prejudicados por alto CC plasmático.

O grupo cetose produziu em média $16,83 \mathrm{~kg}$ de leite, antes de apresentar a doença, contra apenas $13,55 \mathrm{~kg}$ do grupo normal. Isto pode ser uma evidência de que o grupo cetose teria uma produção igual ou maior que o grupo saudável, concordando com os resultados de outros trabalhos que relataram que animais mais produtivos padecem mais de transtornos no metabo-lismo da energia (Herdt et al., 1981; Andersson, 1988; Grohn et al., 1989; Kauppinen, 1983; Andersson e Emanuelson, 1985). Infelizmente não foi possível comparar a produção de leite dos dois grupos em toda a lactação e nas lactações anteriores para verificar realmente qual seria o grupo mais produtivo.

Os níveis de glicose plasmática do grupo cetose foram mais baixos na primeira semana. Butler et al. (1982), e Grummer (1995), relataram que o nadir energético ocorreu durante as duas primeiras semanas de lactação, e considerando que este grupo produzia em média $3 \mathrm{~kg}$ de leite a mais, pode-se sugerir que sofreram um déficit energético mais dramático que o grupo saudável nesta fase.

Os níveis plasmáticos de AST foram maiores $(P<0,05)$ na segunda e terceira semana para o grupo cetose, sugerindo que nesta fase houve um maior aumento da atividade gluconeogênica (Zurek et al., 1994), a ponto de causar lesões nos hepatócitos. Tem sido proposto que níveis plasmáticos altos de AST e AGNE com níveis baixos de glicose são úteis para avaliar a infiltração de gordura no fígado (Roberts e Reid, 1986), mas infelizmente neste experimento não foram feitas biópsias hepáticas e nem quantificados os níveis de $A G N E$, impedindo o uso e avaliação da fórmula indicada por estes autores. 
A análise do ECC e peso dos animais (Tabela 7 do anexo), mostrou que o grupo cetose teve maior condição corporal ao parto $(P<0,0069)$, porém perdeu mais peso $(P<0,0007)$, e mais $E C C(P<0,0068)$, do que o grupo saudável até a $8^{a}$ semana, sendo que a perda foi de $81 \mathrm{~kg}$ e 1,09 pontos no $E C C$, contra uma perda de apenas $37 \mathrm{~kg} \mathrm{e} 0,724$ pontos no ECC no grupo saudável. Isto foi devido ao fato de que após o parto, a vaca experimenta uma dramática redução no consumo de MS (Bertics et al., 1992; Vazquez-Anon et al., 1994), e que nas vacas mais gordas este efeito foi mais pronunciado (Santos, 1996). Além disso, Palmquist e Eastridge (1991) concluíram que altos níveis de CC também deprimiram o consumo de MS em vacas com balanço negativo de energia.

Embora o grupo cetose tivesse parido com ECC significativamente maior do que o grupo saudável, isto não permitiu concluir que os animais com melhor condição corporal ao parto tiveram maiores riscos de padecer de cetose. Entretanto foi suficiente para sugerir que as vacas muito condicionadas ao parto deve no mínimo ser evitado.

Com relação à incidência de doenças (Tabela 8 do anexo), não foi observada através do teste Qui-quadrado nenhuma diferença entre os grupos. Este resultado está de acordo com outras pesquisas que também não puderam evidenciar estas diferenças (Garnsworthy et al., 1987; Ruegg e Milton, 1995; Gearhart et al., 1990; Butler e Smith, 1989; Garnsworthy et al., 1987; Garnsworthy, 1988; Santos, 1996). Porém, houve uma tendência no grupo cetose apresentar mais problemas de retenção de placenta (RP), infecção uterina e claudicação, do que o grupo saudável. Baseados nos resultados deste experimento e nos relatos de outras pesquisas, concluiu-se que ainda se faz necessária mais pesquisas para determinar se realmente há um impacto da cetose em outras doenças. 


\subsection{Avaliação do efeito da condição corporal ao parto}

Para avaliar se houve efeito da condição corporal ao parto sobre a produção de leite e teor de gordura no leite, níveis plasmáticos de BHBA, glicose e AST e incidência de doenças, as vacas foram divididas em dois grupos, gorda e magra, de acordo com sua condição corporal no dia do parto. Os grupos foram ECC maior ou igual a 4 ( $E C C \geq 4,0$ ), para as vacas do grupo gorda, e ECC menor ou igual a $3,5(E C C \leq 3,5)$, para as vacas do grupo magra. Os tratamentos foram diferentes entre si $(P<0)$, e apresentaram uma média de 4,2 e 3,2 para os grupos gorda e magra respectivamente.

Analisando a média geral das 8 semanas (Tabela 9 do anexo), a produção de leite, o teor de gordura no leite, glicose e AST plasmáticas não foram afetados pelo ECC ao parto. Em seu estudo, Santos (1996), também não encontrou efeito de ECC ao parto, na produção e composição do leite, mas encontrou BHBA plasmático mais alto nas vacas gordas, embora não significativo. BHBA foi significativamente mais alto para o grupo gorda $(\mathrm{P}<$ $0,0084)$ devido a perda de peso ter sido mais intensa nas vacas utilizadas neste grupo.

Quando analisada semanalmente (Tabela 10 do anexo), a glicose foi significativamente menor no grupo gorda durante a primeira e segunda semana $(\mathrm{P}<0$ e $\mathrm{P}<0,008$ respectivamente), e com tendência a ser mais baixa nas demais. Concordando com este resultado, este grupo também apresentou BHBA maior que o grupo magra durante as semanas $1(P<0,009), 2(P<0)$ e $3(P<0,004)$, sendo que o pico ocorreu na $1^{\text {a }}$ e $2^{a}$ semana para ambos os grupos.

A análise do peso e ECC (Tabela 11 do anexo), revelou que o peso ao parto, a perda de peso e a perda de ECC no pós-parto foram maiores e diferentes $(\mathrm{P}<0,000, \mathrm{P}<0,010$ e $\mathrm{P}<0$ respectivamente), para o grupo 
gorda, sendo que este grupo pesou $99 \mathrm{~kg}$ a mais que o grupo magra e perdeu em média $25 \mathrm{~kg}$ a mais. De acordo com Santos (1996), as vacas que perdem mais peso no pós-parto tem maior dificuldade em aumentar o consumo de MS, $\mathrm{e}$ as vacas que perdem menos peso atingem o nadir energético mais cedo e aumentam mais precocemente o consumo voluntário. Se for considerado que a mobilização de reservas corporais pode representar um aumento nos níveis plasmáticos de AGNE (Pethick e Dunshea, 1993), estes dados reforçam os resultados de pequisas anteriores onde vacas que estavam mais gordas mobilizaram mais reservas corporais e tenderam a perder mais peso do que as demais (Treacher at al., 1986; Reid et al., 1986; Pedron et al., 1993), havendo uma relação inversa entre consumo de alimento e mobilização de gordura conforme demostrados em várias pesquisas (Bertics at al., 1992; Studer et al., 1993; Grummer, 1993; Vazquez-Anon et al., 1994).

Entretanto não houve diferença na incidência de cetose (Tabela 12 do anexo), entre os grupos $(P<0,119)$. Isto concorda com resultados de pesquisas anteriores que também não puderam associar alta condição corporal ao parto e incidência de doenças metabólicas (Garnsworthy et al., 1987; Ruegg e Milton, 1995; Butler e Smith, 1989; Gearhart et al., 1990; Santos, 1996).

Através deste experimento pôde-se verificar que o ECC ao parto não afetou a produção de leite, gordura do leite, glicose e AST plasmáticas e a incidência de doenças no periodo pós-parto. Todavia os animais com melhor condição corporal ao parto, portanto com maior reserva corporal, perderam significativamente mais peso $(P<0,010)$ nas primeiras oito semanas de lactação. Com base nos níveis de BHBA, pode-se sugerir que as vacas mais gordas ao parto estavam mais predispostas aos transtornos no metabolismo energético, no entanto esta ainda não foi uma condição suficiente para determinar sua maior incidência. 


\subsection{Avaliação do efeito de perda de peso}

Nesta última análise as vacas foram agrupadas de acordo com a variação que tiveram no peso ao parto até a oitava semana de lactação. Os tratamentos foram perda de peso maior que $40 \mathrm{~kg}$ ( $\Delta$ peso $>40$ ), para o grupo que emagreceu mais e perda de peso menor que $30 \mathrm{~kg}$ ( $\Delta$ peso $<30$ ), para o grupo que emagreceu menos. 0 objetivo foi verificar o efeito da perda de peso no período pós-parto sobre a produção de leite e teor de gordura no leite, níveis plasmáticos de BHBA, glicose e AST e incidência de doenças. As médias dos grupos foram diferentes entre si $(P<0)$, apresentando uma média aproximada de perda de peso de $86 \mathrm{~kg}$ para o grupo que emagreceu mais e 10 $\mathrm{kg}$ para o grupo que emagreceu menos.

De acordo com os resultados apresentados na tabela 13 do anexo, observamos que não houve efeito de perda de peso sobre os níveis de glicose, AST e BHBA no período total de 8 semanas. Todavia, quando se analisa semanalmente (Tabela 14 do anexo), BHBA foi significativamente maior durante a segunda e terceira semanas para as vacas que emagreceram mais $(P<0$ e $P<0,008$ respectivamente), e a incidência de cetose foi maior neste grupo $(P<0)$. Segundo Grummer (1995), a excessiva mobilização de reservas corporais leva a um maior risco de doenças metabólicas. Os resultados apresentados também concordam com relatos de outros autores onde as mudanças no ECC entre o final de gestação, parto e início da lactação tem sido responsabilizadas por baixar a performance pós-parto e aumentar a incidência de transtornos metabólicos em vacas de leite (Wildman et al., 1982, Rueg et al., 1992),

Os animais que emagreceram mais produziram significativamente menos leite $(P<0,029)$. Segundo Pedron et al. (1993), os tecidos mobilizados pela vaca leiteira podem suportar 350 a $450 \mathrm{~kg}$ de leite nas 
primeiras semanas de lactação, entretanto, a intensa perda de peso e condição corporal no grupo que emagreceu mais (Tabela 15 do anexo), associados à cetose explicam a baixa produção de leite neste grupo. A tabela 15 do anexo mostra ainda que houve uma forte tendência do ECC e o peso ao parto serem maiores nas vacas que emagreceram mais $(P<0,097$ e $P<0,059$ respectivamente), e como era de se esperar, a perda de condição corporal foi significativamente maior no grupo que emagreceu mais $(P<0,001)$.

A incidência de cetose e claudicação (Tabela 16 do anexo), foi maior no grupo que emagreceu mais, e houve uma tendência em haver mais problemas de retenção de placenta e infecção uterina neste grupo. 


\section{CONCLUSÕES}

A incidência de cetose no rebanho estudado foi de $13,55 \%$. 0 pico de incidência ocorreu na primeira e segunda semana de lactação e houve uma tendência em ser maior em vacas mais velhas.

Os testes de campo aplicados ao leite foram eficientes para monitorar vacas com altos níveis de corpos cetônicos somente após a fase de colostro. A sensibilidade dos testes quando comparadas com BHBA plasmático foi de $76 \%$.

A cetose afetou negativamente a produção de leite no início da lactação e ocorreu tanto em vacas com ECC $\geq 4,0$ quanto em vacas com $E C C \leq 3,5$ ao parto, mas ocorreu principalmente nas vacas que perderam em média acima e $80 \mathrm{~kg}$ de peso e 1 ECC, e não esteve associada às demais doenças que ocorreram neste período.

A condição corporal ao parto $\geq 4,0$ não afetou a produção de leite ou a incidência de doenças no período pós-parto.

As vacas que tiveram uma mobilizaçao de reservas corporais mais intensa (perderam em média mais de $80 \mathrm{~kg}$ de peso e perderam em torno de 1 ECC), produziram significativamente menos leite e apresentaram maior 
incidência de cetose e problemas de casco, sendo portanto mais prejudicial do que a própria condição corporal ao parto.

Em conclusão, a cetose de vacas leiteiras de alta produção é um problema metabólico complexo, relacionado à intensa mobilização de reservas corporais. Seus efeitos na performance lactacional só poderão ser completamente elucidados se também forem analisados os níveis dos hormônios e demais metabólitos que influenciam a lactogênese e os fatores que afetam o consumo voluntário. 
ANEXO 
Tabela 1 - Composição da dieta em ingredientes.

\begin{tabular}{lc}
\hline & \multicolumn{1}{c}{ Dieta } \\
\cline { 2 - 3 } Ingrediente & \% de MS na dieta \\
\hline Silagem de milho & \\
Milho moído & 44.70 \\
Soja grão & 28.28 \\
Farelo de soja $^{2}$ & 7.62 \\
Caroço de algodão & 9.52 \\
Minerais e vitaminas $^{3}$ & 7.62 \\
\hline
\end{tabular}

${ }^{1}$ Silagem de milho contendo uréia.

${ }^{2}$ Farelo de soja com $45 \%$ de proteína bruta.

${ }^{3}$ Fósforo, 5.5\% ; Cálcio, 22\%; Magnésio, 3.5\%; Enxofre, 2.2\%; Sódio, 7.0\%; Cloreto, 10.8\%; Manganês, 1250 ppm; Ferro, 500 ppm; Cobre, 450 ppm; Zinco, 1550 ppm; Selênio, 20 ppm; Vit. A, 90000 UI/kg; Vit. D, $75000 \mathrm{UI} / \mathrm{kg}$; Vit. E $1000 \mathrm{UI} / \mathrm{kg}$. 
Tabela 2 - Composição média da dieta em nutrientes ${ }^{1}$.

\begin{tabular}{lr}
\hline Nutrientes & $\%$ na MS \\
\hline Matéria seca & 48,0 \\
Proteína bruta & 16,0 \\
Fibra detergente ácido & 23,47 \\
Fibra detergente neutro & 38,89 \\
Extrato etéreo & 4,5 \\
Matéria mineral & 5,5 \\
Estrativo não nitrogenado & 53,0 \\
NDT $^{2}$ & 69,0 \\
\hline
\end{tabular}

${ }^{1}$ Resultados analíticos expressos em 100\% de MS.

${ }^{2}$ Nutrientes digestíveis totais, valor estimado. 
Tabela 3. Casos de cetose $^{1}$ e semana de lactação.

\begin{tabular}{rccccccccc}
\hline & \multicolumn{10}{c}{ Semanas pós-parto } \\
Cetose & 1 & 2 & 3 & 4 & 5 & 6 & 7 & 8 \\
\hline Positivo & 7 & 9 & 5 & 2 & 0 & 1 & 0 & 1 \\
$\%$ & 6 & 8,49 & 4.8 & 1.96 & 0.0 & 1 & 0.0 & 1.04 \\
& & & & & & & & \\
Total $^{2}$ & 118 & 105 & 104 & 102 & 100 & 100 & 95 & 96 \\
& & & & & & & & \\
\hline
\end{tabular}

${ }^{1}$ Casos clínicos e subclínicos, considerados como tendo concentrações plasmáticas acima de $10 \mathrm{mg} / \mathrm{dl}$ com e sem sinais clínicos respectivamente.

${ }^{2}$ Até o final do experimento 22 vacas foram eliminadas seja por descarte ou morte. 
Tabela 4 - Número de vacas com cetose $^{1}$ e ordem de lactação.

\begin{tabular}{rcccccc}
\hline Cetose & \multicolumn{7}{c}{ Ordem de } & Lactação & \\
& 1 & 2 & 3 & 4 & 5 & $>5$ \\
\hline Positivo & 0 & 4 & 4 & 1 & 2 & 5 \\
$\%$ & 0 & 10 & 14.28 & 5.55 & 60 & 25 \\
& & & & & & \\
Total $^{2}$ & 7 & 40 & 28 & 18 & 5 & 20 \\
\hline
\end{tabular}

${ }^{1}$ Casos clínicos e subclínicos, considerados como tendo concentrações plasmáticas acima de $10 \mathrm{mg} / \mathrm{dl}$ com e sem sinais clínicos respectivamente.

${ }^{2}$ Até o final do experimento 22 vacas foram descartadas. 
Tabela 5 Efeito de BHBA sobre a média geral ${ }^{1}$ dos parâmetros metabólicos e de produção de leite.

\begin{tabular}{lccc}
\hline & \multicolumn{2}{c}{ Grupos $^{2}$} & \\
\cline { 2 - 3 } Item $^{1}$ & cetose $(\mathrm{n}=11)$ & saudável $(\mathrm{n}=74)$ & $\mathrm{P}<$ \\
\hline Leite, $\mathrm{kg} / \mathrm{dia}$ & 19,93 & 23,84 & $0,058^{*}$ \\
Gordura do leite, $\%$ & 3,62 & 3,47 & 0,158 \\
BHBA, mg/dl & 5,92 & 2,97 & $0 *$ \\
Glicose, mg/dl & 47,26 & 45,70 & 0,395 \\
AST, UI & 78,37 & 76,15 & 0,685 \\
\hline
\end{tabular}

${ }^{1}$ Média das primeiras oito semanas após o parto.

${ }^{2}$ Média dos valores de todas vacas do grupo. 
Tabela 6 - Efeito de $\mathrm{BHBA}^{\top}$ sobre a média semanal dos parâmetros metabólicos e de produção.

\begin{tabular}{|c|c|c|c|c|c|c|c|c|c|}
\hline \multirow[b]{2}{*}{ Item } & \multirow[t]{2}{*}{ Grupos } & \multicolumn{8}{|c|}{ Semanas } \\
\hline & & 1 & 2 & 3 & 4 & 5 & 6 & 7 & 8 \\
\hline & cetose & 16,83 & 17,86 & 18,09 & 19,74 & 21,51 & 20,63 & 22,03 & 22,75 \\
\hline Leite & saudável & 13,55 & 22,36 & 22,83 & 24,80 & 25,76 & 26,14 & 26,66 & 27,62 \\
\hline \multirow[t]{2}{*}{$\mathrm{kg} / \mathrm{dia}$} & $\mathrm{P}<$ & 0,184 & 0,054 & $0,014^{*}$ & $0,030^{*}$ & 0,069 & $0,018^{*}$ & $0,047^{*}$ & $0,037^{*}$ \\
\hline & cetose & 4,11 & 3,98 & 4,09 & 3,02 & 3,45 & 3,49 & 3,39 & 3,45 \\
\hline Gord $^{2}$ & saudável & 4,20 & 3,51 & 3,52 & 3,36 & 3,26 & 3,22 & 3,32 & 3,41 \\
\hline \multirow[t]{2}{*}{$\%$} & $\mathrm{P}<$ & 0,743 & $0,035^{*}$ & $0,013^{*}$ & 0,133 & 0,436 & 0,227 & 0,792 & 0,863 \\
\hline & cetose & 7,61 & 12,43 & 8,14 & 4,29 & 3,11 & 4,61 & 3,41 & 3,74 \\
\hline BHBA $^{1}$ & saudável & 3,87 & 3,15 & 3,11 & 2,92 & 2,63 & 2,74 & 2,65 & 2,66 \\
\hline \multirow[t]{2}{*}{$\mathrm{mg} / \mathrm{dl}$} & $P<$ & $0^{*}$ & $0^{*}$ & $0^{*}$ & $0,031^{*}$ & 0,450 & $0,003^{*}$ & 0,231 & 0,090 \\
\hline & cetose & 48,30 & 41,38 & 45,53 & 47,72 & 49,53 & 46,43 & 49,02 & 50,16 \\
\hline Gluc $^{3}$. & saudável & 53,10 & 45,57 & 43,84 & 44,50 & 44,22 & 44,92 & 45,03 & 45,18 \\
\hline \multirow[t]{2}{*}{$\mathrm{mg} / \mathrm{dl}$} & $P<$ & $0,040^{*}$ & 0,073 & 0,469 & 0,168 & $0,023^{*}$ & 0,519 & 0,088 & $0,033^{*}$ \\
\hline & cetose & 82,45 & 98,45 & 96,54 & 91,27 & 70,18 & 66,00 & 62,36 & 59,72 \\
\hline $\mathrm{AST}^{4}$ & saudável & 75,71 & 77,25 & 77,85 & 76,01 & 74,05 & 76,67 & 77,29 & 74,37 \\
\hline UI & $P<$ & 0,452 & $0,018^{*}$ & $0,037^{*}$ & 0,089 & 0,666 & 0,234 & 0,096 & 0,103 \\
\hline
\end{tabular}

\footnotetext{
'Beta-hidroxibutirato.

${ }^{2}$ Gordura do leite.

${ }^{3}$ Glicose.

${ }^{4}$ Aspartato-aminotransferase.
} 
Tabela 7 -Efeito de BHBA sobre a condição corporal e peso.

\begin{tabular}{|c|c|c|c|}
\hline \multirow[b]{2}{*}{ Ítem } & \multicolumn{2}{|c|}{ Grupos $^{1}$} & \multirow[b]{2}{*}{$P<$} \\
\hline & cetose $(n=11)$ & $\begin{array}{c}\text { saudável } \\
(n=74)\end{array}$ & \\
\hline ECC ao parto & 3,88 & 3,52 & $0,006^{*}$ \\
\hline ECC final ${ }^{2}$ & 2,79 & 2,80 & 0,945 \\
\hline Perda de $E C C^{3}$ & $-1,09$ & $-0,72$ & $0,006^{*}$ \\
\hline Peso ao parto, $\mathrm{kg}$ & 614 & 587 & 0,207 \\
\hline Peso final ${ }^{2}$ & 533,72 & 550,02 & 0,457 \\
\hline Perda de peso ${ }^{3}, \mathrm{~kg}$ & $-81,18$ & $-37,20$ & $0,0007^{*}$ \\
\hline
\end{tabular}

${ }^{1}$ Média dos valores de todas vacas do grupo.

${ }^{2}$ Observação na $8_{-}^{\mathrm{a}}$ semana.

${ }^{3}$ Observação da $8_{-}^{a}$ semana menos a $1_{-}^{\text {a }}$ semana. 
Tabela 8 - Efeito de BHBA sobre a incidência de doenças'.

\begin{tabular}{lcccc}
\hline \multicolumn{1}{c}{ İtem } & $\begin{array}{c}\text { Grupo cetose } \\
(n=11)\end{array}$ & $\begin{array}{c}\text { Grupo saudável } \\
(\mathrm{n}=74)\end{array}$ & $\left(x^{2}\right)$ & $\mathrm{P}<$ \\
\hline Distocia & 1 & 10 & 0,166 & 0,683 \\
Retenção de Placenta ${ }^{2}$ & 6 & 26 & 0,744 & 0,389 \\
Infecção uterina & 9 & 49 & 1,075 & 0,300 \\
Hipocalcemia & 0 & 1 & 0,150 & 0,698 \\
Mastite & 0 & 4 & 0,624 & 0,430 \\
Claudicação & 2 & 6 & 1,140 & 0,286 \\
Cisto ovariano & 2 & 11 & 0,081 & 0,776 \\
\hline
\end{tabular}

${ }^{1}$ Número de vacas com pelo menos 1 semana apresentando sintomas.

${ }^{2}$ Por pelo menos 12 horas após o parto. 
Tabela 9 - Efeito de ECC ao parto sobre a média total ${ }^{1}$ dos parâmetros metabólicos e de produção.

\begin{tabular}{lccc}
\hline & \multicolumn{2}{c}{ Grupos $^{2}$} \\
\cline { 2 - 3 } Ítem & gorda $(n=23)$ & magra $(\mathrm{n}=65)$ & $\mathrm{P}<$ \\
\hline Leite, kg/dia & 23,70 & 23,10 & 0,704 \\
Gordura do leite, \% & 3,57 & 3,47 & 0,218 \\
BHBA, mg/dl & 4,11 & 3,13 & $0,008^{*}$ \\
Glicose, mg/dl & 44,68 & 46,73 & 0,101 \\
AST, UI & 75,93 & 77,90 & 0,650 \\
\hline
\end{tabular}

${ }^{1}$ Média das primeiras oito semanas após o parto.

${ }^{2}$ Média dos valores de todas vacas do grupo. 
Tabela 10 - Efeito de ECC ao parto ${ }^{1}$ sobre a média semanal dos parâmetros metabólicos e de produção.

\begin{tabular}{|c|c|c|c|c|c|c|c|c|c|}
\hline \multirow[b]{2}{*}{ Item } & \multirow[t]{2}{*}{ Grupos } & \multicolumn{8}{|c|}{ Semanas } \\
\hline & & 1 & 2 & 3 & 4 & 5 & 6 & 7 & 8 \\
\hline & gorda & 15,30 & 22,86 & 22,71 & 24,08 & 25,57 & 26,08 & 26,03 & 27,02 \\
\hline Leite & magra & 12,87 & 21,31 & 23,10 & 24,30 & 25,25 & 25,20 & 25,80 & 26,96 \\
\hline \multirow[t]{2}{*}{ kg/dia } & $\mathrm{P}<$ & 0,214 & 0,394 & 0,829 & 0,904 & 0,878 & 0,629 & 0,899 & 0,976 \\
\hline & gorda & 4,45 & 3,67 & 3,95 & 3,12 & 3,20 & 3,39 & 3,28 & 3,46 \\
\hline Gord $^{2}$. & magra & 4,21 & 3,54 & 3,42 & 3,32 & 3,27 & 3,23 & 3,34 & 3,42 \\
\hline \multirow[t]{2}{*}{$\%$} & $P<$ & 0,272 & 0,465 & $0,002^{*}$ & 0,255 & 0,695 & 0,381 & 0,739 & 0,836 \\
\hline & gorda & 5,63 & 6,40 & 4,92 & 3,16 & 3,19 & 3,40 & 3,08 & 3,13 \\
\hline BHBA $^{\prime}$ & magra & 4,15 & 3,71 & 3,27 & 3,09 & 2,56 & 2,87 & 2,73 & 2,73 \\
\hline \multirow[t]{2}{*}{$\mathrm{mg} / \mathrm{dl}$} & $P<$ & $0,009^{*}$ & $0^{*}$ & $0,004^{*}$ & 0,832 & 0,269 & 0,356 & 0,540 & 0,488 \\
\hline & gorda & 47,38 & 41,90 & 43,20 & 46,36 & 44,77 & 42,96 & 45,88 & 44,97 \\
\hline Gluc ${ }^{3}$. & magra & 54,93 & 46,57 & 44,75 & 44,51 & 44,99 & 45,66 & 46,01 & 46,41 \\
\hline \multirow[t]{2}{*}{$\mathrm{mg} / \mathrm{dl}$} & $P<$ & $0 *$ & $0,008^{*}$ & 0,383 & 0,298 & 0,902 & 0,129 & 0,941 & 0,420 \\
\hline & gorda & 77,86 & 79,91 & 83,86 & 86,56 & 74,56 & 68,47 & 66,91 & 69,30 \\
\hline $\mathrm{AST}^{4}$ & magra & 75,70 & 82,63 & 80,78 & 75,86 & 74,58 & 78,58 & 79,58 & 75,50 \\
\hline UI & $\mathrm{P}<$ & 0,767 & 0,710 & 0,673 & 0,143 & 0,997 & 0,167 & 0,083 & 0,397 \\
\hline
\end{tabular}

${ }^{1}$ Beta-hidroxibutirato.

${ }^{2}$ Gordura do leite.

${ }^{3}$ Glicose.

${ }^{4}$ Aspartato-aminotransferase. 
Tabela 11 - Efeito de ECC ao parto sobre a condição corporal e peso.

\begin{tabular}{lccc}
\hline & \multicolumn{2}{c}{ Grupos $^{1}$} & \\
\cline { 2 - 4 } Ítem & gorda $(\mathrm{n}=23)$ & magra $(\mathrm{n}=65)$ & $\mathrm{P}<$ \\
\hline ECC ao parto & 4,29 & 3,29 & $0^{*}$ \\
ECC final ${ }^{2}$ & 3,02 & 2,71 & $0,0003^{*}$ \\
Perda de ECC ${ }^{3}$ & $-1,27$ & $-0,57$ & $0^{*}$ \\
Peso ao parto, $\mathrm{kg}$ & 663 & 564 & $0^{*}$ \\
Peso final $^{2}$ & 603,39 & 529,38 & $0^{*}$ \\
Perda de peso $^{3}, \mathrm{~kg}$ & $-59,60$ & $-34,61$ & $0,010^{*}$ \\
\hline
\end{tabular}

${ }^{1}$ Média dos valores de todas vacas do grupo.

${ }^{2}$ Observação na $8_{-}^{a}$ semana.

${ }^{3}$ Observação da $8_{-}^{a}$ semana menos a $1_{-}^{a}$ semana. 
Tabela 12 - Efeito de ECC ao parto sobre a incidência de doenças' ${ }^{1}$.

\begin{tabular}{lcccc}
\hline \multicolumn{1}{c}{ Ítem } & $\begin{array}{c}\text { Grupo gorda } \\
(n=23)\end{array}$ & $\begin{array}{c}\text { Grupo magra } \\
(n=65)\end{array}$ & $\left(x^{2}\right)$ & $\mathrm{P}<$ \\
\hline Cetose & 5 & 6 & 2,930 & 0,119 \\
Distocia & 1 & 11 & 2,280 & 0,130 \\
R P & 11 & 24 & 0,840 & 0,359 \\
Infecção uterina & 14 & 45 & 0,538 & 0,463 \\
Hipocalcemia & 1 & 0 & 2,860 & 0,091 \\
Mastite & 1 & 3 & 0,003 & 0,958 \\
Claudicação & 4 & 3 & 3,790 & 0,052 \\
Cisto ovariano & 5 & 7 & 1,736 & 0,188 \\
\hline
\end{tabular}

${ }^{1}$ Número de vacas com pelo menos 1 semana apresentando sintomas.

${ }^{2}$ Retenção de placenta por pelo menos 12 horas após o parto. 
Tabela 13 - Efeito de perda de peso sobre a média total ${ }^{1}$ dos parâmetros metabólicos e de produção.

\begin{tabular}{lccc}
\hline & \multicolumn{3}{c}{ Grupos $^{2}$} \\
\cline { 2 - 3 } Ítem $^{1}$ & $\begin{array}{c}\text { Emagreceu mais } \\
(\mathrm{n}=38)\end{array}$ & $\begin{array}{c}\text { Emagreceu menos } \\
(\mathrm{n}=48)\end{array}$ \\
\hline Leite, kg/dia & 22,09 & 25,08 & $0,029^{*}$ \\
Gordura do leite, \% & 3,58 & 3,41 & $0,026^{*}$ \\
BHBA, mg/dl & 3,64 & 3,11 & 0,110 \\
Glicose, mg/dl & 45,92 & 45,94 & 0,983 \\
AST, UI & 77,57 & 76,58 & 0,784 \\
\hline
\end{tabular}

${ }^{1}$ Média das primeiras oito semanas após o parto.

${ }^{2}$ Média dos valores de todas vacas do grupo. 
Tabela 14 - Efeito de perda de peso ${ }^{1}$ sobre a média semanal dos parâmetros metabólicos e de produção.

\begin{tabular}{|c|c|c|c|c|c|c|c|c|c|}
\hline \multirow[b]{2}{*}{ Item } & \multirow[t]{2}{*}{ Grupos } & \multicolumn{8}{|c|}{ Semanas } \\
\hline & & 1 & 2 & 3 & 4 & 5 & 6 & 7 & 8 \\
\hline & E. mais ${ }^{2}$ & 14,22 & 20,16 & 21,14 & 22,48 & 24,03 & 24,19 & 25,03 & 25,48 \\
\hline Leite & E. menos $^{3}$ & 13,26 & 23,74 & 25,60 & 26,51 & 27,22 & 27,68 & 27,55 & 29,05 \\
\hline \multirow[t]{2}{*}{ kg/dia } & $P<$ & 0,566 & $0,022 *$ & $0,004^{*}$ & $0,010^{*}$ & $0,041^{*}$ & $0,026^{*}$ & 0,106 & $0,022^{*}$ \\
\hline & E. mais & 4,38 & 3,70 & 3,85 & 3,27 & 3,35 & 3,33 & 3,42 & 3,30 \\
\hline Gord ${ }^{4}$. & E. menos & 4,20 & 3,44 & 3,32 & 3,30 & 3,15 & 3,18 & 3,23 & 3,46 \\
\hline \multirow[t]{2}{*}{$\%$} & $P<$ & 0,368 & 0,100 & $0,0009 *$ & 0,086 & 0,216 & 0,361 & 0,254 & $0^{*}$ \\
\hline & E. mais & 4,78 & 5,81 & 4,44 & 3,09 & 2,69 & 3,04 & 2,65 & 2,62 \\
\hline $\mathrm{BHBA}^{5}$ & E. menos & 4,10 & 3,06 & 3,11 & 2,96 & 2,78 & 2,98 & 2,93 & 2,97 \\
\hline \multirow[t]{2}{*}{$\mathrm{mg} / \mathrm{dl}$} & $P<$ & 0,169 & $0^{*}$ & $0,008^{*}$ & 0,792 & 0,857 & 0,905 & 0,565 & 0,488 \\
\hline & E. mais & 53,38 & 44,27 & 43,55 & 44,98 & 45,10 & 44,70 & 46,37 & 46,01 \\
\hline Gluc $^{6}$. & E. menos & 53,41 & 45,71 & 43,84 & 45,07 & 43,98 & 45,18 & 45,15 & 45,19 \\
\hline \multirow[t]{2}{*}{$\mathrm{mg} / \mathrm{dl}$} & $P<$ & 0,524 & 0,369 & 0,853 & 0,955 & 0,488 & 0,763 & 0,450 & 0,611 \\
\hline & E. mais & 75,10 & 87,68 & 82,78 & 81,15 & 72,00 & 72,78 & 74,84 & 74,23 \\
\hline $\mathrm{AST}^{7}$ & E. menos & 78,16 & 76,02 & 74,20 & 77,18 & 76,27 & 78,00 & 77,20 & 75,65 \\
\hline UI & $P<$ & 0,604 & $0,048^{*}$ & 0,146 & 0,501 & 0,469 & 0,377 & 0,688 & 0,810 \\
\hline
\end{tabular}

${ }^{1}$ Peso na $8_{-}^{8}$ semana menos peso ao parto.

${ }^{2}$ Grupo que emagreceu mais.

${ }^{3}$ Grupo que emagreceu menos.

${ }^{4}$ Gordura do leite.

${ }^{5}$ Beta-hidroxibutirato.

${ }^{6}$ Glicose.

${ }^{7}$ Aspartato-aminotransferase. 
Tabela 15 - Efeito da perda de peso sobre a condição corporal e peso.

\begin{tabular}{|c|c|c|c|}
\hline \multirow[b]{2}{*}{ Ítem } & \multicolumn{2}{|c|}{ Tratamento $^{1}$} & \multirow[b]{2}{*}{$P<$} \\
\hline & Emagreceu mais & Emagreceu menos & \\
\hline ECC ao parto & 3,67 & 3,53 & 0,097 \\
\hline$E C C$ final $^{2}$ & 2,69 & 2,91 & $0,012^{*}$ \\
\hline Perda de $\mathrm{ECC}^{3}$ & $-0,98$ & $-0,61$ & $0^{*}$ \\
\hline Peso ao parto, $\mathrm{kg}$ & 609,44 & 582,25 & 0,059 \\
\hline Peso final ${ }^{2}$ & 525,81 & 571,68 & $0,001 *$ \\
\hline Perda de peso ${ }^{3}, \mathrm{~kg}$ & $-86,63$ & $-10,56$ & $0^{*}$ \\
\hline
\end{tabular}

${ }^{1}$ Média dos valores de todas vacas do grupo.

${ }^{2}$ Observação na $8_{-}^{a}$ semana.

${ }^{3}$ Observação da $8_{-}^{a}$ semana menos a $1_{-}^{\text {a }}$ semana. 
Tabela 16 - Efeito de perda de peso sobre a incidência de doenças ${ }^{1}$.

\begin{tabular}{lcccc}
\hline \multicolumn{1}{c}{ Ítem } & $\begin{array}{c}\text { Grupo } \\
\text { emagreceu mais } \\
(\mathrm{n}=38)\end{array}$ & $\begin{array}{c}\text { Grupo } \\
\text { emagreceu } \\
\text { menos }(\mathrm{n}=48)\end{array}$ & $\begin{array}{l}\left(x^{2}\right) \\
\mathrm{P}<\end{array}$ \\
\hline Cetose & 9 & 0 & 12,697 & $0 *$ \\
Distocia & 6 & 5 & 0,549 & 0,459 \\
RP $^{2}$ & 17 & 15 & 1,651 & 0,199 \\
Infecção uterina & 27 & 28 & 1,488 & 0,220 \\
Hipocalcemia & 0 & 1 & 0,801 & 0,371 \\
Mastite & 0 & 3 & 2,461 & 0,117 \\
Claudicação & 8 & 2 & 5,885 & $0,015 *$ \\
Cisto ovariano & 6 & 8 & 0,012 & 0,913 \\
\hline
\end{tabular}

${ }^{1}$ Número de vacas com pelo menos 1 semana apresentando sintomas.

${ }^{2}$ Retenção de placenta por após pelo menos 12 horas após o parto. 


\section{REFERÊNCIAS BIBLIOGRÁFICAS}

ANDERSSON, L. Subclinical ketosis in dairy cows. Veterinary Clinics of North America. Food Animal Practice, v.4, p.233-51, 1988.

ANDERSSON, R. Ketone bodies as risk factors for metabolism disturbances and mastitis. Milch Praxis, v.31, n.4, p.200-201, 1993. / Resumo em CAB Abstracts on CD-ROOM, 1993-4/95.

ANDERSSON, L.; EMANUELSSON, $U$. An epidemiological study of hiperketonaemia in Swedish dairy cows; determinants and the relation to fertility. Preventive Veterinary Medicine, v.3, p.449-62, 1985.

ANDERSSON, R.; GUSTAFSSON, A.H. Use of milk acetone measurements as a counselling aid. Result for the first of three test years. Meddelande Svensk Husdjursskotsel, n.162, p.19-25, 1990. / Resumo em CAB Abstracts on CD-ROOM, 1993-4/95.

ANNUAL REPORT OF THE NORWEGIAN CATTLE DISEASE RECORDINGSYSTEM FOR 1991. Arsmelding fra Helsekortutvalget Helsekortordninga 1991, Norway, Norske Veterinaerforening. Norsk Veterinaertidsskrift, v.104, n.6, p.467-480, 1992. / Resumo em CAB Abstracts on CD-ROOM, 1993-4/95. 
BAIRD, G.D. Primary ketosis in high yelding dairy cow. Clinical and subclinical disorders, prevention and outlook. Journal of Dairy Science, v.65, p.1-10, 1982.

BAUMAN, D. E.; CURRIE, W. B. Partitioning of nutrients during pregnancy and lactation: A review of mecanism involving homeortasis and homeorhesis. Journal of Dairy Science, v.63, p.1514, 1980.

BEAUDEAU, F.; FRANKENA, K.; FOURICHON, C.; SEEGERS, H.; FAYE, B.; NOORDHUIZEN, J. P. T. M. Associations between health disorders of French dairy cows and early and late culling within the lactation. Preventive Veterinary Medicine, v.19, p.213-231, 1994.

BENDIXEN, P.H.; VILSON, B.; EKESBO, I.; ASTRAND, D.B. Disease frequencies in dairy cows in Sweden. IV. Ketosis. Preventive Veterinary Medicine, v.5, p.99-109, 1987.

BERGMAN, E.N. Hyperketonemia-ketogenesis and ketone body metabolism. Journal of Dairy Science, v.54, n.6, p.936-948, 1970.

BERGMAN, E.N.; SELLERS, A.F. Comparison of fasting ketosis in pregnant and nonpregnant guinea pigs. American Journal of Physiology, n.198, p.1083, 1960.

BERTICS, S.J.; GRUMMER, R.R.; CADORNIGA-VALINO, C.; STODDARD, E.E. Effect of prepartum dry matter intake on liver triglyceride concentration and early lactation. Journal of Dairy Science, v.75, p.1914, 1992. 
BLOOD, D. C. ; RADOSTITIS, O. M.; HENDERSON, J. A. Veterinary Medicine. 6. ed. London; Baillière Tindall, p. 996-1006, 1986.

BUTLER, W.R.; EVERETT, R.W.; COPPOCK, C.E. The relationships between energy balance, milk production and ovulation in postpartum Holstein cows. Journal of Animal Science, v.54, p.742, 1982.

BUTLER, W.R.; SMITH, R.D. Interrelationships between energy balance and postpartum reproductive function in dairy cattle. Journal of Dairy Science, v.72, p.767, 1989.

CASTILLO, O. A. C. Aspectos bioquímicos do sangue e do leite de vacas leiteiras no inicio da lactação. Belo Horizonte, 1994. 77p. (Dissertação) Mestrado - Universidade Federal de Minas Gerais.

CURTIS, C.R.; ERB, H.N.; SNIFFEN, C.J.; SMITH, R.D.; KRONFELD, D.S. Path analysis of dry period nutrition, pospart metabolic and reproductive disorders an mastitis in Holstein cows. Journal of Dairy Science, v.68, p.2347-360, 1985.

DETILLEUX, J.C.; GROHN, Y.T.; QUAAS, R.L. Effects of clinical ketosis on test day milk yield in finnish ayshire cattle. Journal of Dairy Science, v.77, n.11, p.3316-3323, 1994.

DOHOO, I.R.; MARTIN, S.W. (1984). Subclinical Ketosis: prevalence and associations with production and disease. Canadian Journal of Comparative Medicine, v.48, p.1-15, 1984. 
DOHOO, I.R.; MARTIN, S.W.; MEEK, A.H.; SANDALS, W.C.D. Disease, production and culling in Holstein-Friesian cows. I. The data. Preventive Veterinary Medicine, v.1, p.321-34, 1983.

DOMECQ, J.J.; SKIDMORE, A.L.; LOID, J.W.; KANEENE, J.B. Validation of body condiction scores with ultrasound measurements of subcutaneous fat of dairy cows. Journal of Dairy Science, v.78, p.2308, 1995.

DRACKLEY, J.K.; RICHARD, M.J.; BEITZ, D.C.; YOUNG, J.W. Metabolic changes in dairy cows with ketonemia in response to feed restriction and dietary 1,3-Butanediol. Journal of Dairy Science, v.75, p.1622-1634, 1992.

DUFFIELD, T.F.; KELTON, D.F.; LESLIE, K.E. A survey of subclinical ketosis in Ontario dairy cattle. Dairy Research Report, n.395, p.24-7, 1995.

EDMONSON, A.J.; LEAN, I.J.; WEAVER, L.D.; FARVER, T.; WEBSTER, G. A body condition scoring chat for Holstein dairy cows. Journal of Dairy Science, v.72, p.68, 1989.

EMANUELSON, U.; OLTENACU, P.A.; GROHN, Y.T. Nonlinear mixed model analyses of five production disordes of dairy cattle. Journal of Dairy Science, v.62, n.9, p.2765-2772, 1993.

EMERY, R.S.; BEL, J.W.; THOMA, J.W. Benefits derived from routine testing of milk ketones. Journal of Sairy Science, v.51, p.867-868, 1968. 
ERB, H.N.; GROHN, Y.T. Epidemiology of metabolic disordes in the periparturient dairy cow. Journal of Dairy Science, v.71, p.2557, 1988.

FATUR, B.; JASBEC, I.; KOPITAR, M.; SKETA, J. Incidence of clinical and subclinical forms of bovine ketosis in Slovenia and some other European countries. Prvi Slovenski Veterinarski, Portoroz, 18-20, november 1993. Zbornik, 1993. p.165-170. / Abstracts on CD-ROOM, 1993-4/95.

FERGUSON, J.D. Nutrition and reproduction in dairy cows. Dairy nutrition management. In the Veterinary Clinics of North America. Food Animal Practice, v.7, p.483, 1991.

FERGUSON, J.D.; BYERS, D.; FERRY, J.; JOHNSON, P.; RUEGG, P.; WEAVER, L. Round table discussion: Body condition of lactating cows. Agri-Practice, v.15, p.17, 1994.

FRANKLIN, S.T.; YOUNG, J.W.; NONNECKE, B.J. Effects of ketones, acetate, butyrate, and glicose on bovine lymphocyte proliferation. Journal of Dairy Science, v.74, p.2507, 1991.

FRONK, T.J.; SHULTZ, L.H.; HARDIE, A.R. Effect of dry period conditioning on subsequent metabolic disorders and performance of dairy cows. Journal of Dairy Science, v.63, p.1080-90, 1980.

GARNSWORTHY, P.C.; TOPPS, J.H. The effect of body condition of dairy cows at calving on their food intake and performance when given complete diets. Animal Production, v.35, p.113, 1987. 
GARNSWORTHY, P.C. The effect of energy resserves at calving on performance of dairy cows. In: Nutrition and Lactation in the Dairy Cow. Butterworths, 1988, p.157.

GEARHART, M.A.; CURTIS, C.R.; ERB, H.N.; SMITH, R.D.; SNIFFEN, C.J. CHASE, L.E.; COOPER, M.D. Relationship of change in condiction score to cow health in Holsteins. Journal of Dairy Science, v.73, p.3132, 1990.

GRANT, R.J.; ALBRIGHT, J.L. Feeding behaviour and management factors during the transition period in dairy cattle. Journal of Animal Science, v.73, p.2791, 1995.

GREGORY, R.; McELVEEN, J.; TATTERSALL, R.B.; TODD, I. The effects of 3-hydroxybutyrate and glicose on human $T$ cell responses to Candida albicans. Immunology and Medical Microbiology, v.7, n.4, p.315-320, 1993. / Resumo em CAB Abstracts on CD-ROOM, 1993-4/95.

GRÖHN, Y.T.; ERB H.N.; MC CULLOCH, C.E.; SALONIEMI, H.S. Epidemiology of metabolic Disorders in dairy cattle: association among host characteristics, disease and production. Journal of Dairy Science, v.72, p.1876-85, 1989.

GRUMMER, R.R. Etiology of lipid-related metabolic disorders in periparturient dairy cows. Journal of Dairy Science, v.76, n.12, p.3882-3896, 1993.

GRUMMER, R.R. Impact of changes organic nutrient metabolism on feeding the transition dairy cow. Journal of Animal Science, v.73, p.2810, 1995. 
GUARD. C. Fresh cow problems are costly; culling hurts the most. Hoards Dairyman, v.141, n.1, p-8, 1996.

GUSTAFSSON, A.H.; ANDERSSON, L.; EMANUELSSON, U. Effect of hiperketonaemia, feeding frequency and intake of concentrate and energy on milk yeld in dairy cows. Animal Production, v.56, p.51-60, 1993.

HAGERT, C. Continuous control of energy and protein supply of the dairy cow at peak lactation by means of acetone, urea, protein and fat concentrations in milk. Medizinische Tierklinik, Tierarztliche Fakultat, 1991. 126p. / Resumo em CAB Abstracts on CD-ROOM, 1993-4/95.

HERDT, T.H.; STEVENS, J.B.; OLSON, W.G.; LARSON. Blood concentrations of b-hydroxybutyrate in clinicalli normal Holstein-Friesian herds and in a high prevalence of ketosis. American Journal of Veterinary Research, v.42, p.503-6, 1981.

HERDT, T. H. Fuel homeostasis in the ruminant. Veterinary Clinics of North America. Food Animal Practice, v.4, p.213-232, 1988.

HIBBITT, A.G. Bovine ketosis and its prevention. Veterinary Record, v.7, p.13-15, 1979.

HOVE, K. Insulin secretion in lactanting cows: response to glicose infused intravenously in normal, ketonemic, and starved animals. Journal of Dairy Science, v.61, p.1407-13, 1978. 
HU, Y.; SANDERS, J.D.H.; KURZ, S.G.; OTTOBRE, J.S.; DAY, M.L. In vitro prostaglandin production by bovine corpora lutea destined to be normal or short-lived. Biology Reproductive, v.42, p.801, 1990.

INTERNATIONAL FEDERATION OF CLINICAL CHEMISTRY, Commitee on Standards, Part 2. IFCC Method for Aspartate Aminotransferase, Amsterdam, Elsevier Scientific Publishing Company, 1975.

JOHNSON, M.M.; PETERS, J.P. Technical note: an improved method to quantify nonesterified fatty acids in bovine plasma. Journal of Animal Science, v.71, p.753, 1993.

JONES, W.P.; HANSEN, L.B.; CHESTER-JONES, H. Response of health care to selection for milk yield of dairy cattle. Journal of Animal Science, v.77, n.10, p.3137-3152, 1994.

JORDAN, E.R.; FOURDRAINE, R.H. Characteration of the management practices of the top milk producing herds in the country. Journal of Dairy Science, v.76, n.10, p.3247-3256, 1993.

KANDEFER-SZERSZEN, M.; FILAR, J.; SZUTER-CIESIELSKA, A; RZESKI, W. Suppression of interferon response of bovine leukocytes during clinical and subclinical ketosis in lactating cows. Deutsche Tierarztliche Wochenschrift, v.99, n.11, p.440-443, 1992. / Resumo em CAB Abstracts on CD-ROOM, 1993-4/95.

KANEKO, J.J. Clinichal Biochemistry of Domestic Animals. 3ed, New York, Academic Press, Inc, 1980. p.46-48. 
KAUPPINEN, K. Prevalence of bovine ketosis in relation to number and satage of lactation. Acta Veterinary Scandinavica, v.24, p.349-61, 1983.

KEGL, T. Control of ketonuric by administration of glucocorticoids in Holstein Friesian cows after calving. Magyar Allatorvosok Lapja, v.47, n.4, p.162-163, 1992. / Resumo em CAB Abstracts on CD-ROOM, 1993-4/95.

KEGL, T.; GAAL, T. Ketonuric index - a new practical indicator to evaluate the energy balance of dairy cows. Magyar Allatorvosok Lapja, v.47, n.4, p.159-161, 1992. / Resumo em CAB Abstracts on CD-ROOM, 1993-4/95.

KING, J.O.L. The effects of ketosis in dairy cows on body weight, milk yeld and composition. British Veterinary Journal, n.135, p.40-3, 1979.

KLUCINSKI, W.; MIERNIK-DEGÓRSKA, E.; DEGÓRSKI, A.; TARGOWSKI, S.; WINNICKA, A. Effect of ketone bodies on the mitogenic response of bovine milk lymphocites. Journal of Veterinary Medicinal Association, v.35, p.626-631, 1988.

KLUCINSKI, W.; DEGÓRSKI, A.; MIERNIK-DEGÓRSKA, E.; TARGOWSKI, S.; WINNICKA, A. Effect of ketone bodies on the phagocytic activity of bovine milk macrophages and polymorphonuclear leukocytes. Journal of Veterinary Medicinal Association, v.35, p.632-639, 1988.

KOMARAGIRI, M.; ERDMAN, R.A. Prediction of body tissue mobilization in the dairy cow. In: Proceedings of the Maryland Nutrition Conference for Feed Manufacturers, 1995. p.105. 
KREBS, H.A. Bovine ketosis. Veterinary Record, v.78, p.187-92, 1966.

KREMER, W.D.J.; NOORDHUIZEN-STASSEN, E.N.; GROMMERS, F.J.; SCHUKKEN, Y.H.; HEERINGA, R.; BRAND, A.; BURVENICH, C. Severity of experimental Escherichia coli mastitis in ketonemic and nonketonemic dairy cows. Journal of Dairy Science, v.76, n.11, p.3428-3436, 1993.

KRONFELD, D.S. Major metabolic of milk volume, mammary efficieny, and spontaneous ketosis in dairy cows. Journal of Dairy Science, v.65, p.2204-12, 1982.

KUZMA, R.; ROMANUIK, J. Treatment of cystic ovarian disease (COD) in cows with low fertilitty. II. The influence of some factors on the treatment efficacy. Bulletin of the Veterinary Institute in Pulawy, v.38, n.1, p.31-37, 1994. / Resumo em CAB Abstracts on CD-ROOM, 1993-4/95.

LAMOND, D.R. The influence of undernutrition on reproductionin the cow. Animal Breeding Abstract, v.38, p.359, 1970.

LATOUR, D. et al. "Getting Started with PROC MIXED". SAS Institute Inc, Cary, NC, 121 p. 1994.

LEAN, I.J.; BRUSS, M.L.; BALDWIN, R.L.; TROUTT, H.F. Bovine ketosis: A Review. I. Epidemiology and Pathogenesis. Veterinary Bulletin, v.61, n.12, p.1209-1218, 1991. 
LEAN, I.J.; BRUSS, M.L.; BALDWIN, R.L.; TROUTT, H.F. Bovine ketosis: A Review. II. Biochemistry and Prevention. Veterinary Bulletin, v.61, n.1, p.1-13, 1991

LEAN, I.J.; FARVER, T.B.; TROUTT, H.F.; BRUSS, M.L.; GALLAND, J.C.; BALDWIN, R.L.; HOLMBERG, C.A.; WEAVER, L.D. Time series crosscorrelation analysis of postparturient relationships among serum metabolities and yield variables in Holstein cows. Journal of Dairy Science, v.75, p.1891-1900, 1992.

LINDSTRÖN, U.B.; VON-BONSDORF, M.; SYVÄJÄRVI, J. Factors affecting bovine ketosis and its association with non-return rate. Journal of the Scientific Agricultural Sociey of Finland, v.55, p.497-507, 1984.

LINGAAS, F.; TVEIT, B. Etiology of acetonemia in Norwegian Cattle. 2. Effect of butyric acid, valeric acid, and putrescine. Journal of Dairy Science, v.75, p.2433-2439, 1992.

LITTLEDICK, E.T.; YOUNG, J.W.; BEITZ, D.C. Common metabolic diseases of cattle: Ketosis, milk fever, grass tetany and downer cow complex. Journal of Dairy Science, v.64, p.1465-82, 1981.

LUCEY, S.; ROWLANDS, G.J.; RUSSEL, A.M. Short term associations between disease and milk yeld in dairy cows. Journal of Dairy Research, v.53, p.7-15, 1986. 
MAGALHÃES, A. C. M.; BELÉM, P. A. D. Estudo preliminar sobre a ocorrência de cetose subclínica em um rebanho leiteiro. 7ำ Encontro Nacional ed Patologia Veterinária, ANAIS, 1995.

MARKUSFELD, O. Relationship between overfeeding, metritis and ketosis in high yelding dairy cows. Veterinary Record, n.116, p.489-91, 1985.

MARKUSFELD, O.; NAHARI, N.; ADLER, H. Evaluation of a routine testing for ketonuria and aciduria in the detection of sub and clinical ketosis associated with overfeeding in dairy cattle. The Bovine Practitioner, n.19, p.219-222, 1984.

MARSTORP, P.; ANFALT, T.; ANDERSSON, L. Determination of oxidized ketone bodyes in milk by flow injection analysis. Analytical Chimica Acta, p.149-281, 1983.

MIETTINEN, P.V.A.; SETALA, J.J. Relationships between subclinical ketosis, milk production and fertility in Finnish dairy cattle. Preventive Veterinary Medicine, v.17, n.1/2, p.1-8, 1993.

NEBEL, R.L.; McGILLIARD, M.L. Interactions of high milk yield and reproductive performance in dairy cows. Journal of Dairy Science, v.76, p.3257, 1993.

NEMEC, M.; ZADNIK, T.; KLINKON, M.; JAZBEC, I. Acetone concentration in samples of bulk tank milk. Prvi Slovenski Veterinarski, Portoroz, 18-20, november 1993. Zbornik, 1993. p.37-43. / Abstracts on CD-ROOM, $1993-4 / 95$. 
NIELEN, M.; AARTS, M.G.A.; JONKERS, A.G.M.; WENSING, T.; SCHUKKEN, Y.H. Evaluation of two cow side tests for the detection of subclinical ketosis in dairy cows. Cannadian Veterinary Journal, v.35, p.229, 1994.

NONNECKE, B.J.; FRANKLIN, S.T.; YOUNG, J.W. Effects of ketones, acetate, and glicose on in vitro immunoglobulin secretion by bovine lymphocytes. Journal of Dairy Science, v.75, p.982-990, 1992.

OLDS, D.; COOPER, T.; THRIFT, F.A. Relationships between milk yeld and fertility in dairy cattle. Journal of Dairy Science, v.62, p.1140, 1979.

OLTENACU, P.A.; EKESBO, I. Epidemiological study of clinical mastitis in dairy cattle. Veterinary Research, v.25, n.2-3, p.208-212, 1994. / Abstracts on CD-ROOM, 1993-4/95.

PALMQUIST, D. L.; EASTRIDGE, M. L. Dietary fat effects on milk yeld and composition. California Anim. Nutr. Conf., Fresno. California Grain and Feed Assoc., Sacramento, C.A. 1991.

PATTON, R. A.; BUCHOLTZ, H. F.; SCHMIDT, M. K.; HALL, F. M. Body condition scoring: a management tool. Dairy Guide, East Lansing, Michigan, 6, p., Sept. 1988.

PAYNE, J. M.; PAYNE, S. The metabolic profile test. Oxford university press, Toronto, 179 p. 1987. 
PEDRON, O.; CHELI, F.; SENATORE, E.; BAROLI, D.; RIZZI, R. Effect of body condition score at calving on performance, some blood parameters, and milk fatty acid composition in dairy cows. Journal of Dairy Science, v.76, p.2528, 1993.

PEHRSON, B. Studies on ketosis in dairy cows. Acta Veterinaria Scandinavica, Suplement 15, p.1-55, 1966.

PETHICK, D.W.; DUNSHEA, F.R. Fat metabolism and turnover. In: FORBS, J.M.; FRANCE, J., ed. Quantitative Aspects of Ruminant Digestion and Metabolism. C.A.B. International. 1993. cap.13, p.291-311.

QUIRÓS, J.; MENESES, A.; MORENO, W.; CORDERO, L.; CEDEÑO, H. Diagnostico de la cetosis subclinica en hatos lecheros de alta produccion en Costa Rica. Ciencias Veterinarias, v.15, n.1, p.15-25, 1993.

REID, I. M.; ROBERTS, C. J.; TREACHER, R. J.; WILLIANS, L. A. Effect of body condition at calving on tissue mobilization, developement of fatty liver and blood chemistry of dairy cows. Animal Production, 43:7. 1986.

REITMAN, S.; FRANKEL, S.A. A colorimetric method for the determination of serum glutamic-oxalacetic and glutamic-pyruvic transaminases. American Journal Clinical Pathology, v.28, p.56-63, 1957.

RIEMANN, H.P.; BJERKE LARSSEN, R.; SIEMENSEN, E. Ketosis in Norwegian dairy Herds - some epidemiologic asociations. Acta Veterinaria Scandinavica, v.26, p.482-92, 1985. 
ROBERTS, C. J.; REID, I. M. Fat cow syndrome and subclinical fatty liver. In Howard, J. L. ed: Current Veterinary Therapy, Food Animal Practice, 2 ed. Philadelphia, W. B. Saunders, p. 324-326, 1986.

ROBINSON, A. M.; WILLIAMSON, D. H. Effects of acetoacetate administration on glicose metabolism in mammary gland of fed lactating rats. Biochemical Journal, v.164, p749, 1977.

RUEGG, P.; MILTON, R.L. Body condition score of Holstein cows on Prince Edward Island, Canada: Relationships with milk yield, reproductive performance, and disease. Journal of Dairy Science, v.78, p.552, 1995.

SANTOS, J.E.P. Effect of degree of fatness prepartum on lactational performance and follicular development of early lactating dairy cows. Arizona, 1996. 107p. M.S., University of Arizona.

SCHULTZ, L.H.; MYERS, M. Milk test for ketosis in dairy cows. Journal of Dairy Science, v.42, p.705, 1959.

SHAW, J.C. Ketosis in dairy cattle. A review. Journal of Dairy Science, v.39, p.402-434, 1956.

SPALDING, R.W.; EVERETT, R.W.; ROOT, R.H. Fertility in New York artificially inseminated Holstein herds in dairy herd inprovement. Journal of Dairy Science, v.58, p.718-23, 1975. 
SPICER, L.J.; ECHTERNKAMP, S.E. The ovarian insulin and insulin-like growth factor systems with an emphasis on domestic animals. Domestic Animal Endocrinology, v.12, p.223, 1995.

SPICER, L.J.; ECHTERNKAMP, S.E. Effects of insulin and insulin-like growth factor I, and gonadotropins on bovine granulosa cell proliferation, progesterone production, estradiol production, and (or) insulin -like growth factor I production in vitro. Journal of Animal Science, v.71, p.1232, 1993.

STAPLES, C.R.; THATCHER, W.W. Relationship between ovarian activity and energy status during early postpartum period of high producing dairy cows. Journal of Dairy Science, v.73, p.938, 1990.

STEVENSON, J.S.; BRITT, J.H. Relationships among luteinizing hormone, estradiol, progesterone, glucocorticoids, milk yield, body weight and pospartum ovarian activity in Holstein cows. Journal of Animal Science, v.48, p.570, 1979.

STUDER, V.A.; GRUMMER, R.R.; BERTICS, S.J. Effect of prepartum propylene glycol administration on periparturient fatty liver in dairy cows. Journal of Dairy Science, v.76, p.2931, 1993.

TAGOWSKI, S.P.; KLUCINSKI, W. Reduction in mitogenic response of bovine lymphocytes by ketone bodies. American Journal of Veterinary Research, v.44, p.828-830, 1983. 
TAGOWSKI, S.P.; KLUCINSKI, W.; LITTLEDIKE, E.T.; HOY, D.A. Supression of mitogenic response of bovine lymphocytes during experimental ketosis in calves. American Journal of Veterinary Research, v.46, p.1378-1380, 1985.

TIETZ, N.W. Fundamental of Clinical Chemistry, 2 ed., Philadelphia, Saunders, 1982. 240p.

TVEIT, B.; LINGAAS, F.; SVENDSEN, M.; SJAASTAD, O.V. Etiology oa acetonemia in Norwegian Cattle. 1. Effect of ketogenic silage, season, energy level, and genetic factors. Journal of Dairy Science, v.75, p.24212432, 1992.

VAZQUeZ-ANON, M.; BeRTICS, S.; LUCK, M .; GRUMMER, R.R. Peripartum liver triglyceride and plasma metabolites in dairy cows. Journal of Dairy Science, v.77, p.1521, 1994.

WAKIL, S.J.; BRESSLER, R. Fatty acid metabolism and ketone body metabolism. Metabolism, v.11, p.742, 1962.

WILLADSEN, C.M.; QVSEL, J.; WILLEBERG, P. Ketosis in dairy herds. II. Epidemiologicalinvestigations. Dansk Veterinaertidsskrift, v.76, n.7, p. 275280, 1993. / Resumo em CAB Abstracts on CD-ROOM, 1993-4/95.

WILDMAN, E.E.; JONES, G.M.; WAGNER, P.E.; BOMAN, R.L.; TROUT Jr., H.F.; LESCH, T.N. A dairy body condition scoring system and its relationship to selected production characteristics. Journal of Dairy Science, v.77, p.1556, 1994. 
WILLIANSON, D.H.; MELANBY, J.; KREBS, H.A. Enzymatic determination of D(-)-b-hydroxybutyric acid and acetoacetic acid in blood. Biochemistry Journal, v.82, p.90-6, 1962.

WITTWER, F.G.; HEUER, G.; CONTRERAS, P.A.; BOHMWALD, H. Clinica blood chemistry values of downer cows from the south of Chile. Archivos de Medicina Veterinaria, v.25, n.1, p.83-88, 1993. / Resumo em CAB Abstracts on CD-ROOM, 1993-4/95.

ZIAUDDIN, K.S.; MURALIDHARAN, K.; SESHADRI, S.J.; HUSSAIN, P.M.; SREENIVASAJAH, P.V.; SYED-ZIAUDDIN, K.; MARGOOB-HUSSAIN, P. Incidence of ketonuria among local and crossbred cows - a five year observation. Veterinary Medical Journal, v.16, n.4, p.310-312, $1992 . \quad /$ Resumo em CAB Abstracts on CD-ROOM, 1993-4/95. 
APÊNDICE 


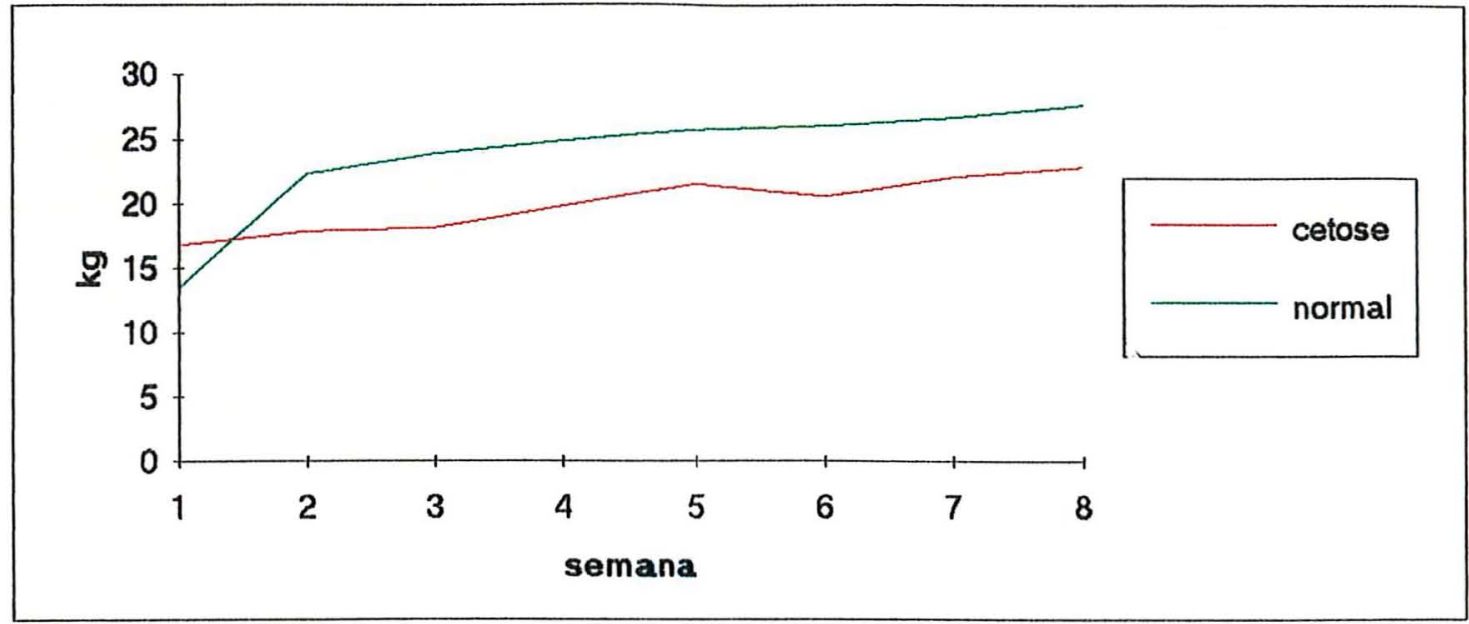

Fig. 1: Efeito de BHBA sobre a produção de leite

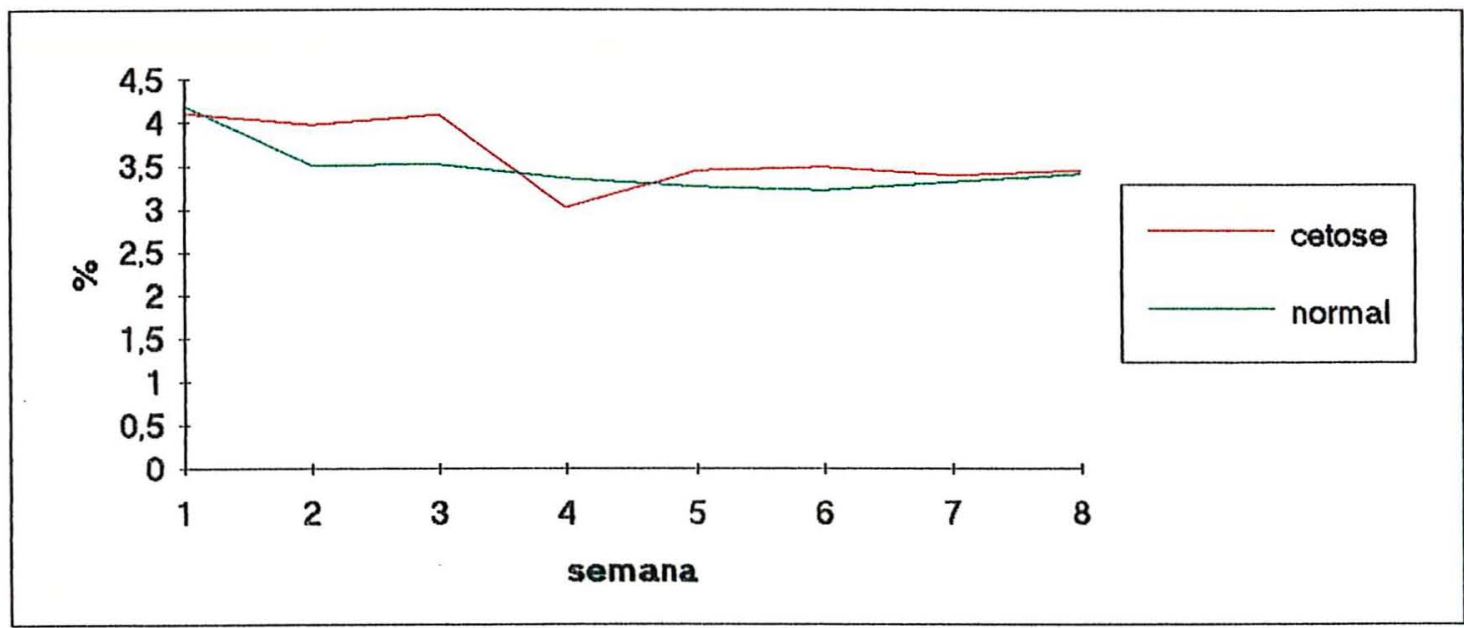

Fig. 2: Efeito de BHBA sobre o teor de gordura do leite.

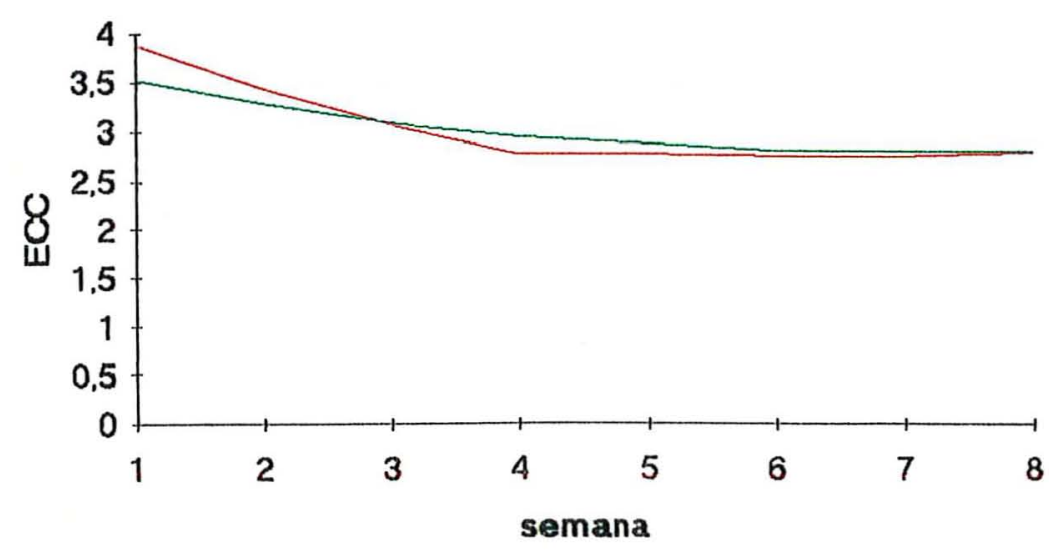

Fig. 3: Efeito de BHBA sobre a condição corporal. 


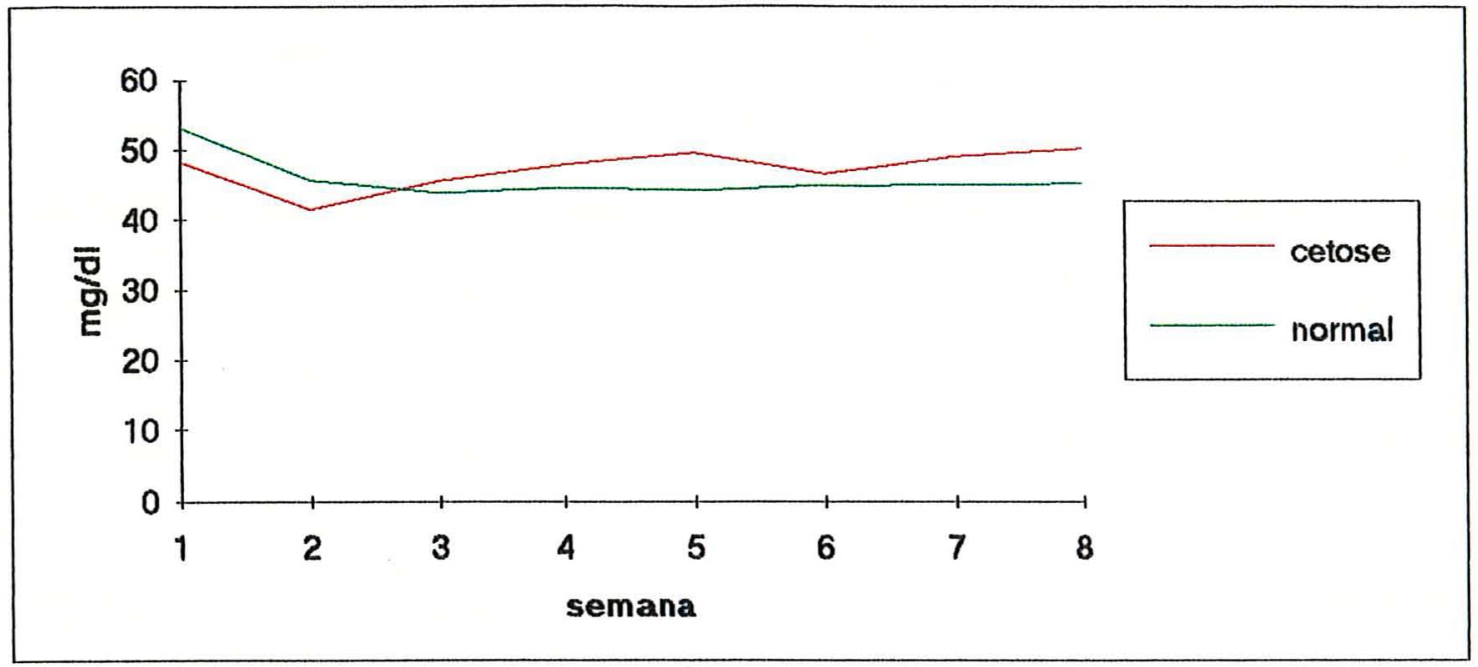

Fig. 4: Efeito de BHBA sobre glucose plasmática

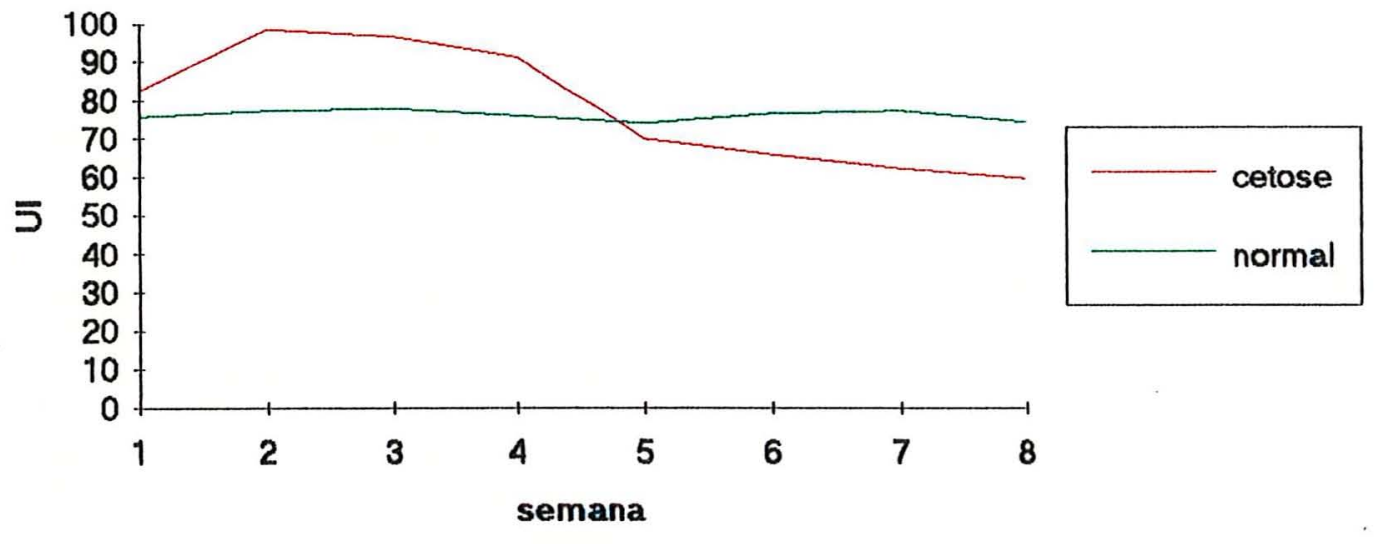

Fig. 5: Efeito de BHBA sobre AST plasmática.

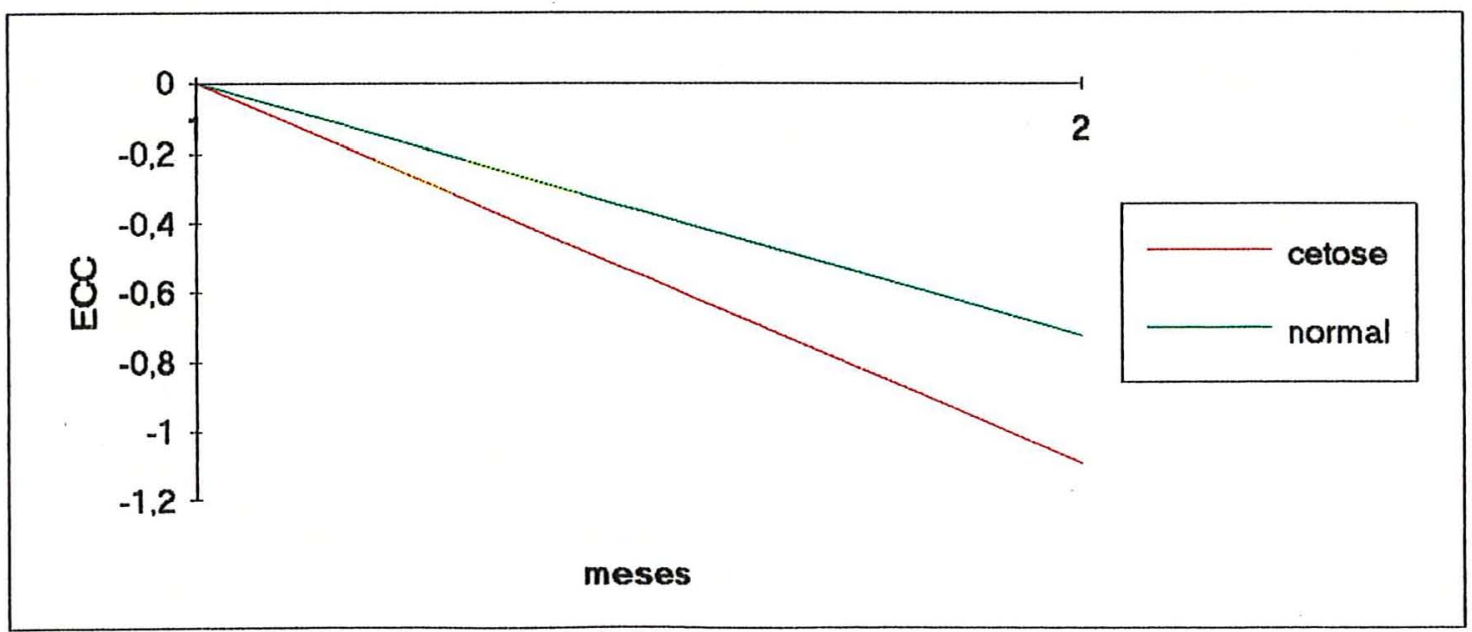

Fig. 6: Efeito de BHBA sobre perda de ECC. 


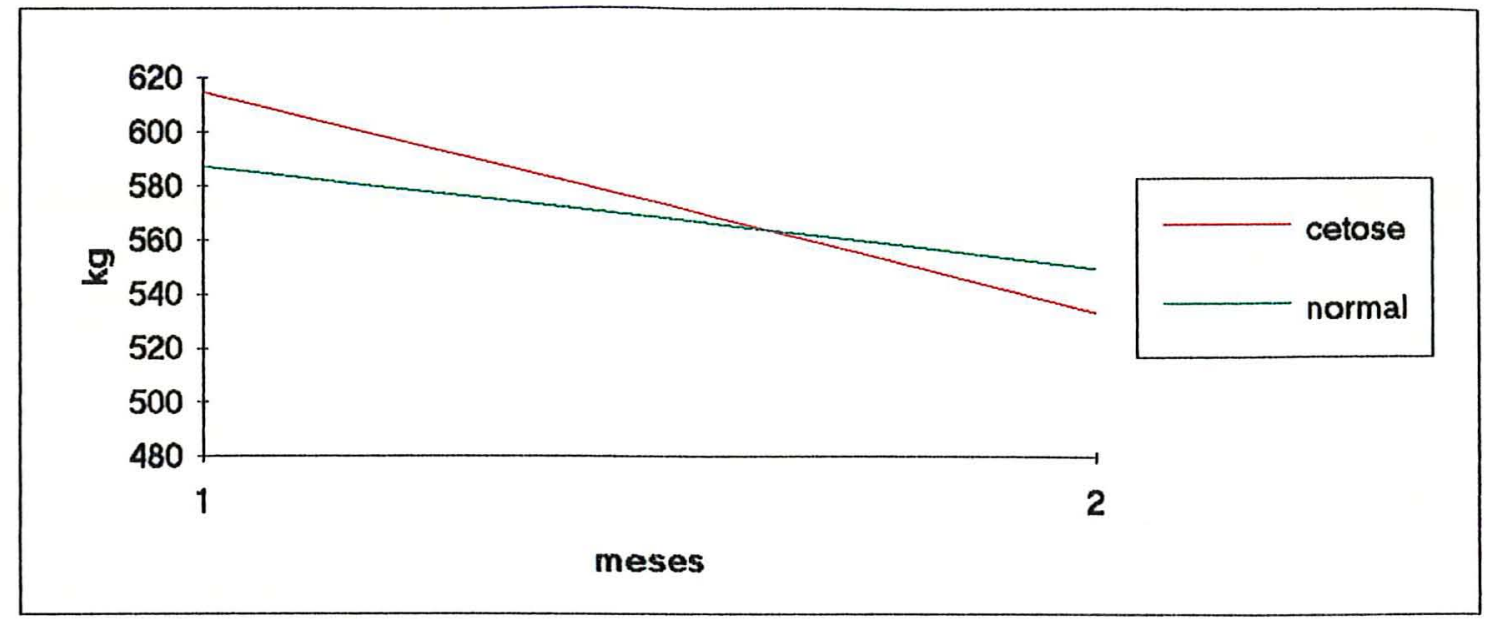

Fig. 7: Efeito de BHBA sobre o peso vivo.

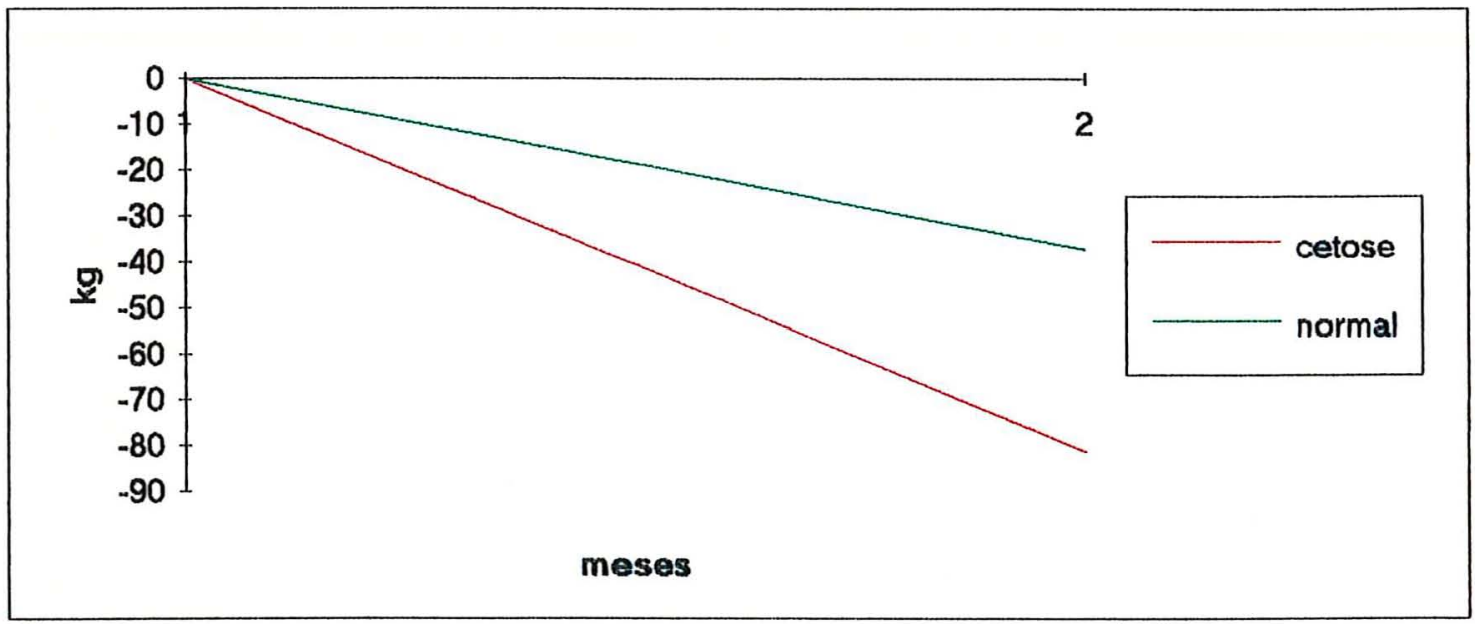

Fig. 8: Efeito de BHBA sobre a perda de peso.

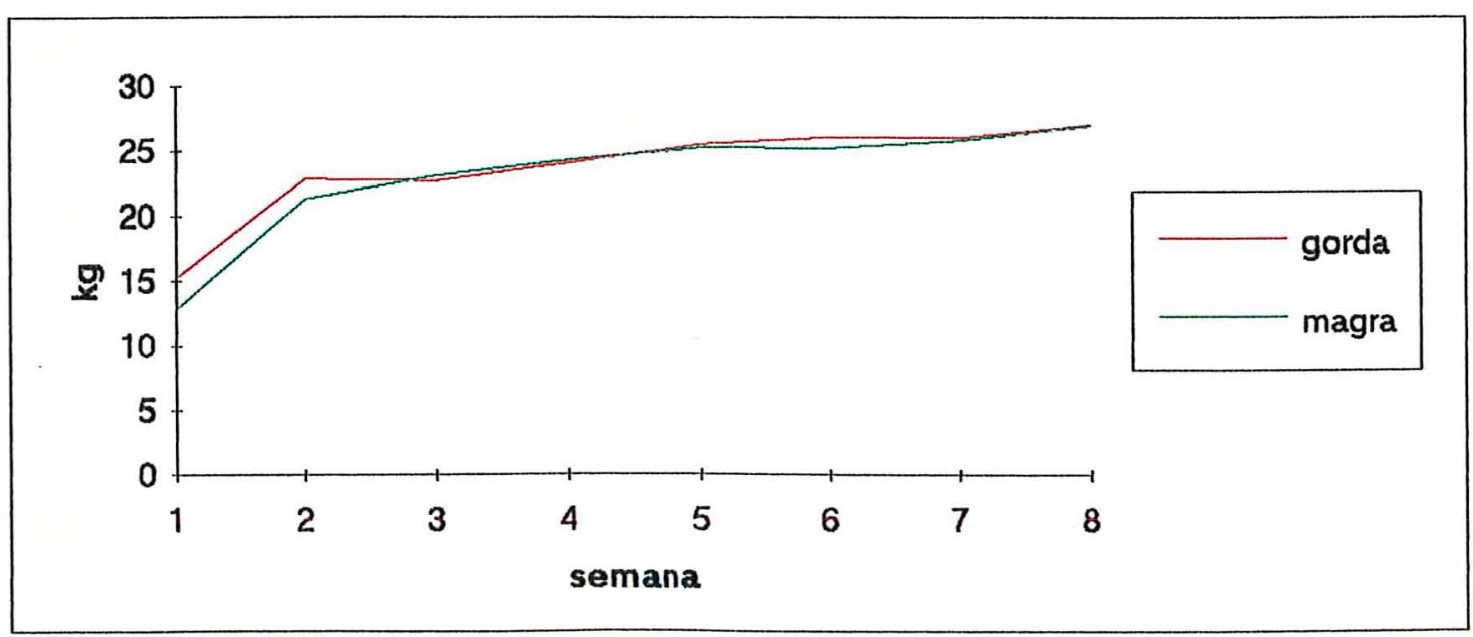

Fig. 9: Efeito de ECC ao parto sobre a produção de leite. 


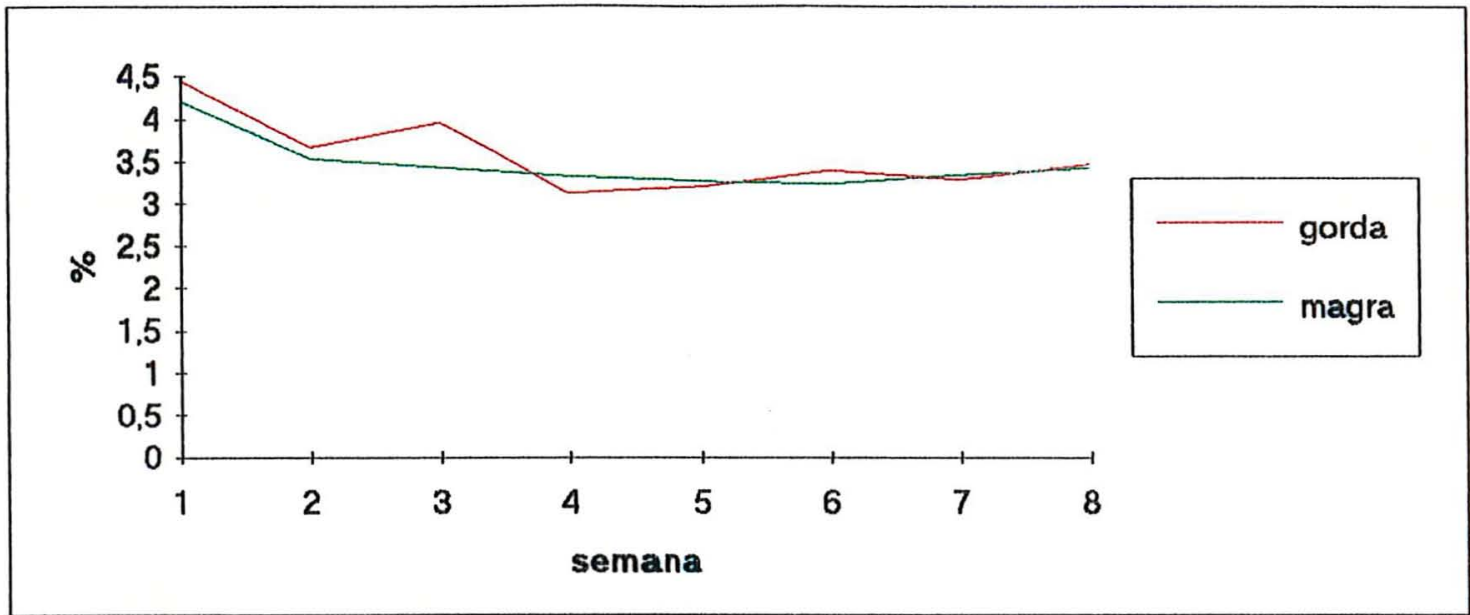

Fig. 10: Efeito do ECC ao parto sobre o teor de gordura do leite.

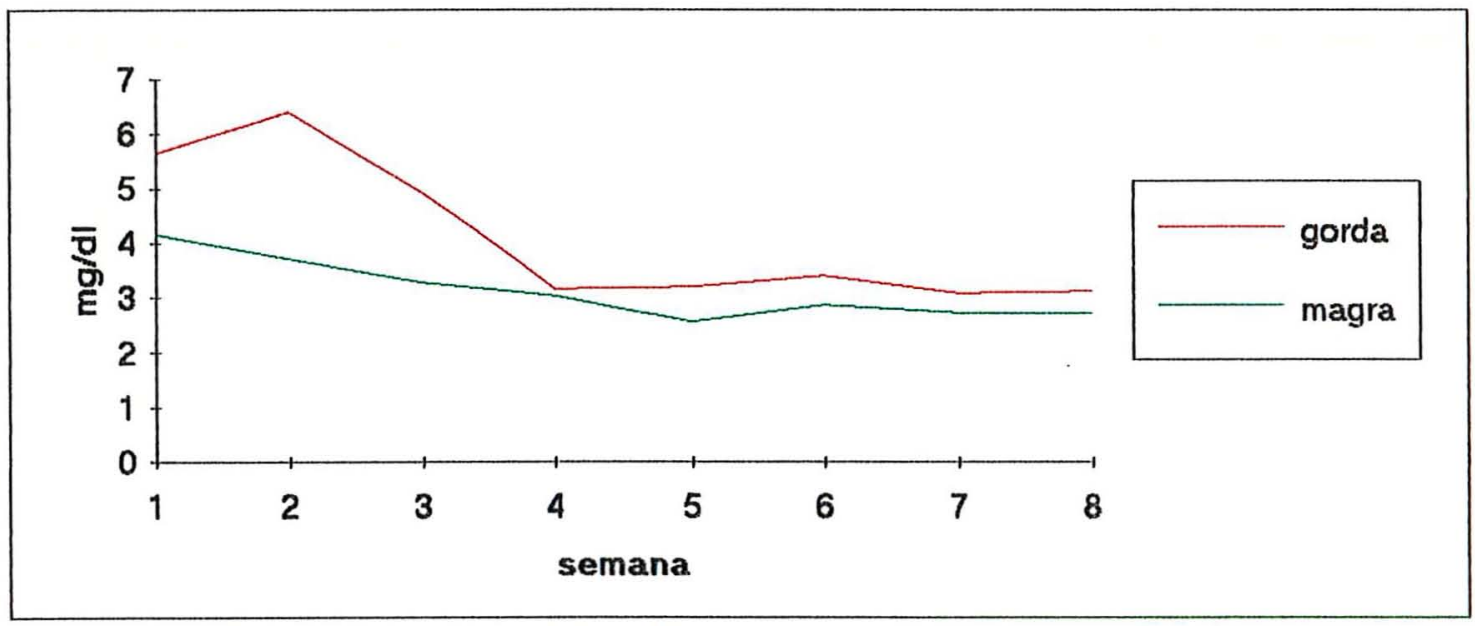

Fig. 11: Efeito do ECC ao parto sobre o BHBA pasmático.

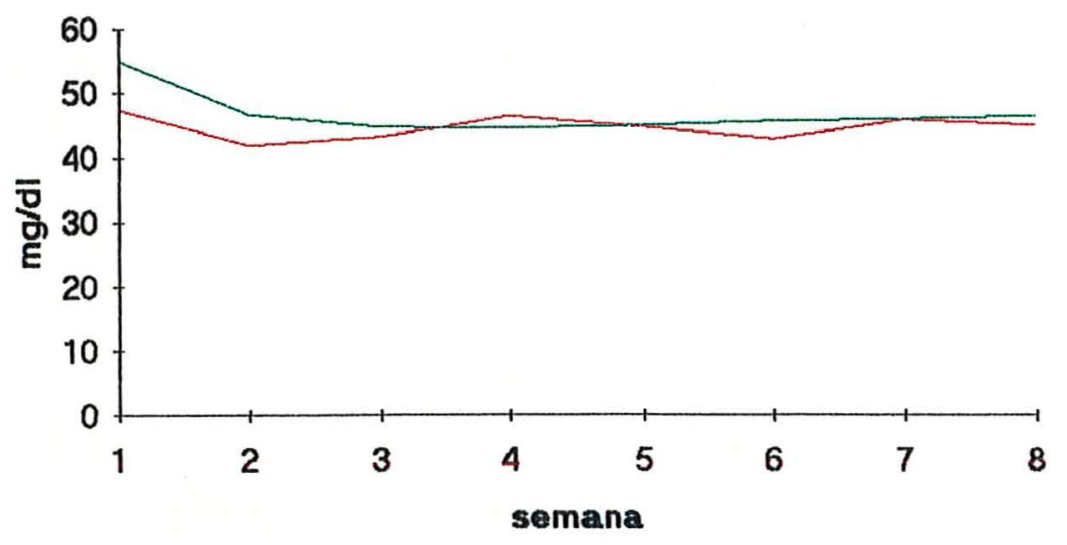

Fig. 12: Efeito de ECC ao parto sobre glucose plasmática. 


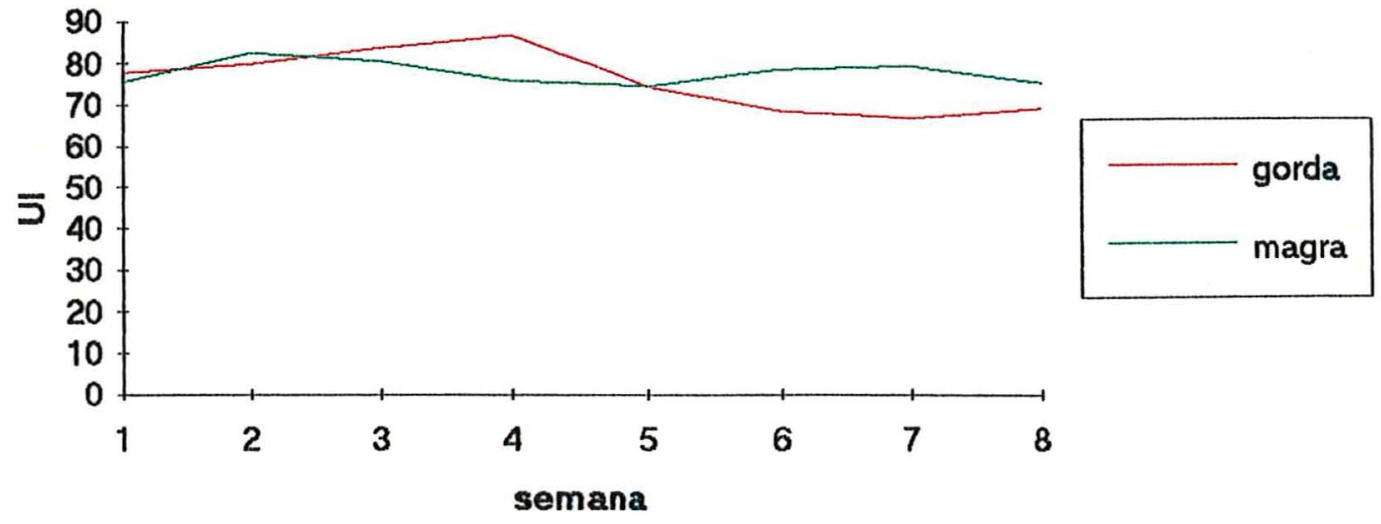

Fig. 13: Efeito de ECC ao parto sobre AST plasmática.

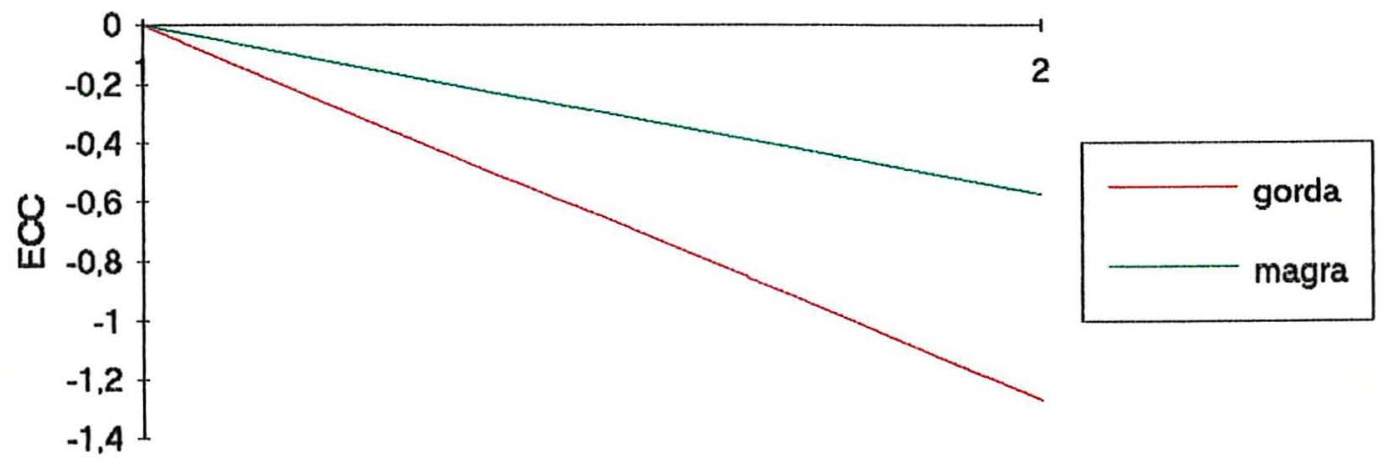

meses

Fig. 14: Efeito de ECC ao parto sobre a perda de ECC.

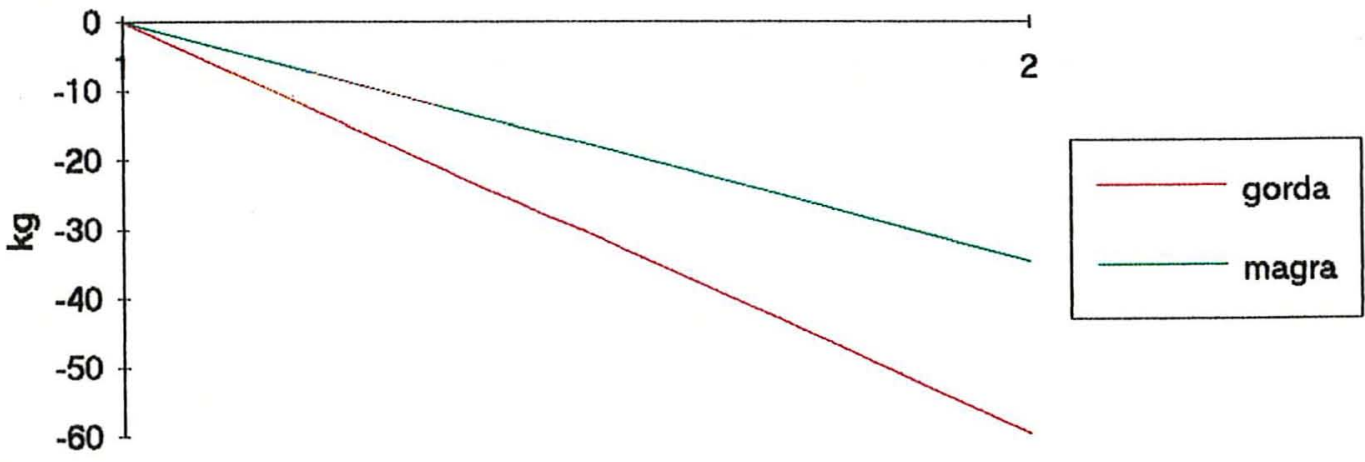

meses

Fig. 15: Efeito de ECC ao parto sobre a perda de peso. 


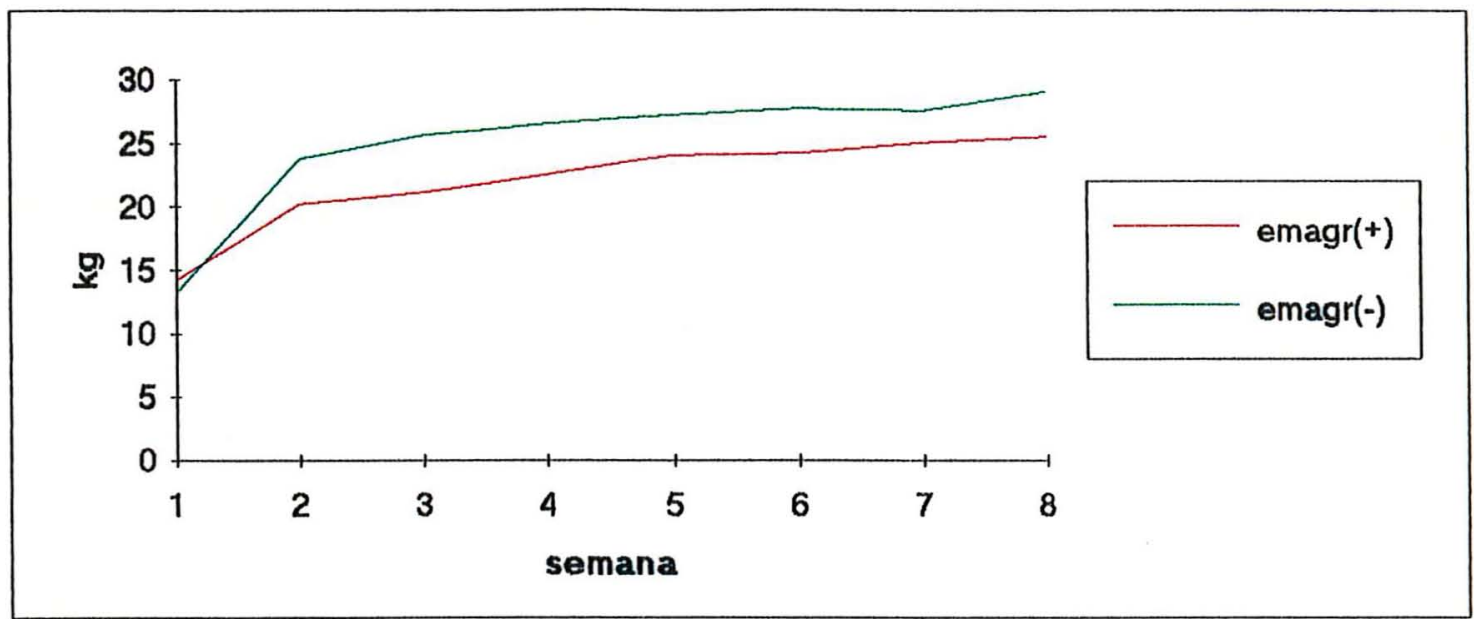

Fig. 16: Efeito de perda de peso sobre a produção de leite.

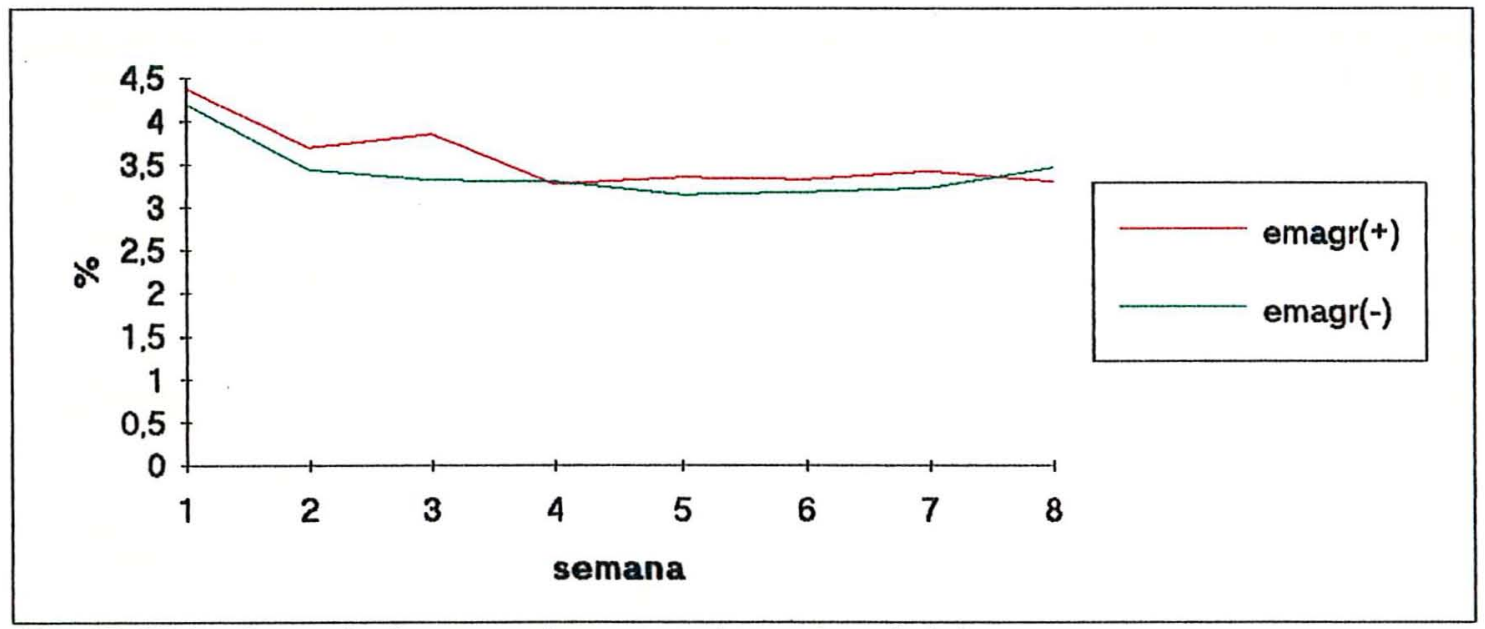

Fig. 17: Efeito de perda de peso sobre o teor de gordura do leite.

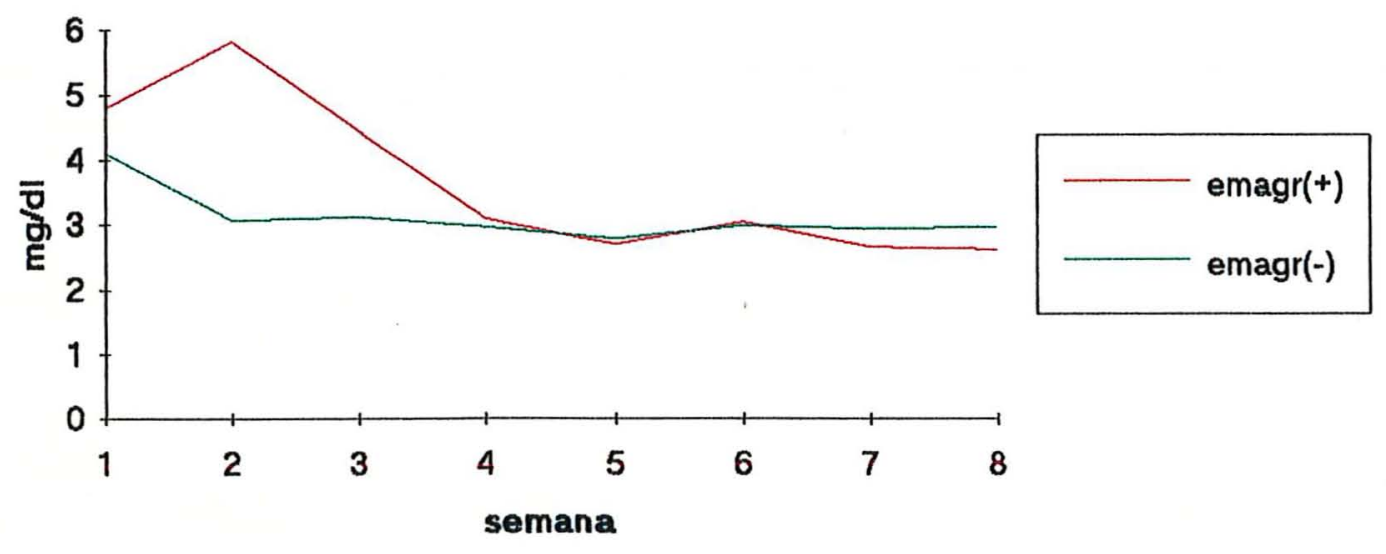

Fig. 18: Efeito de perda de peso sobre BHBA plasmático. 


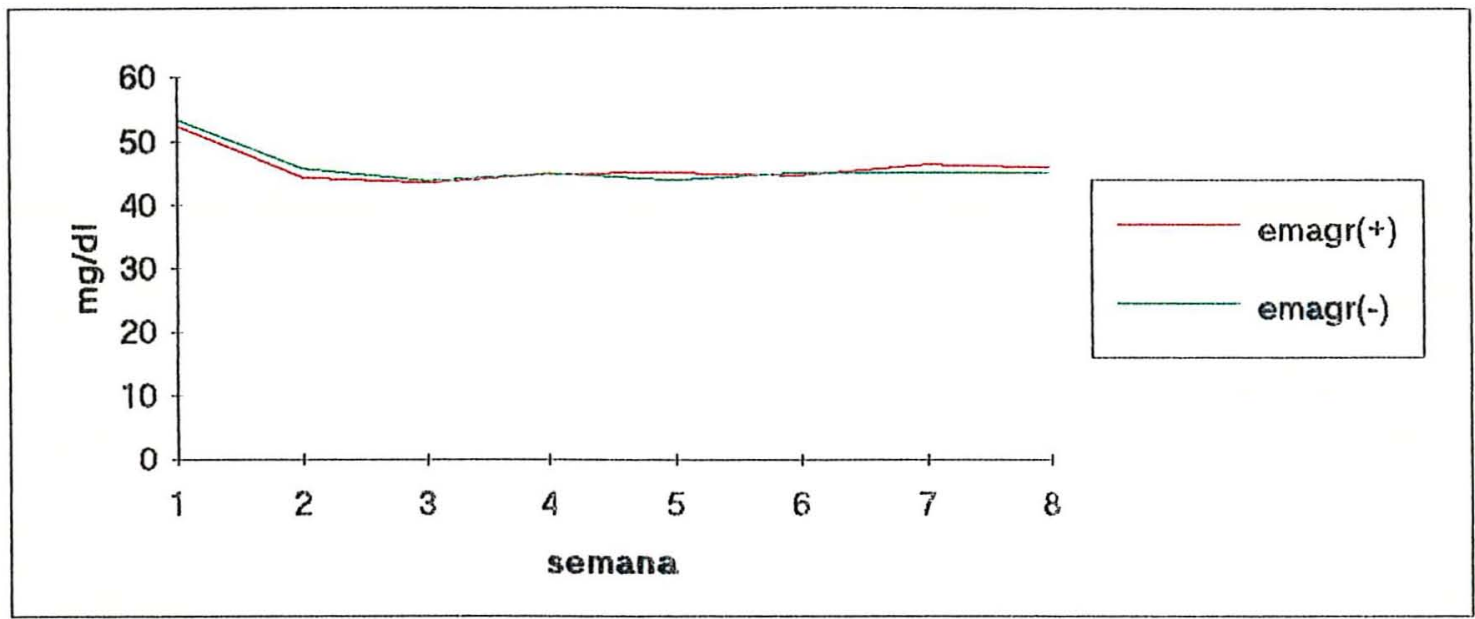

Fig. 19: Efeito de perda de peso sobre glucose plasmática.

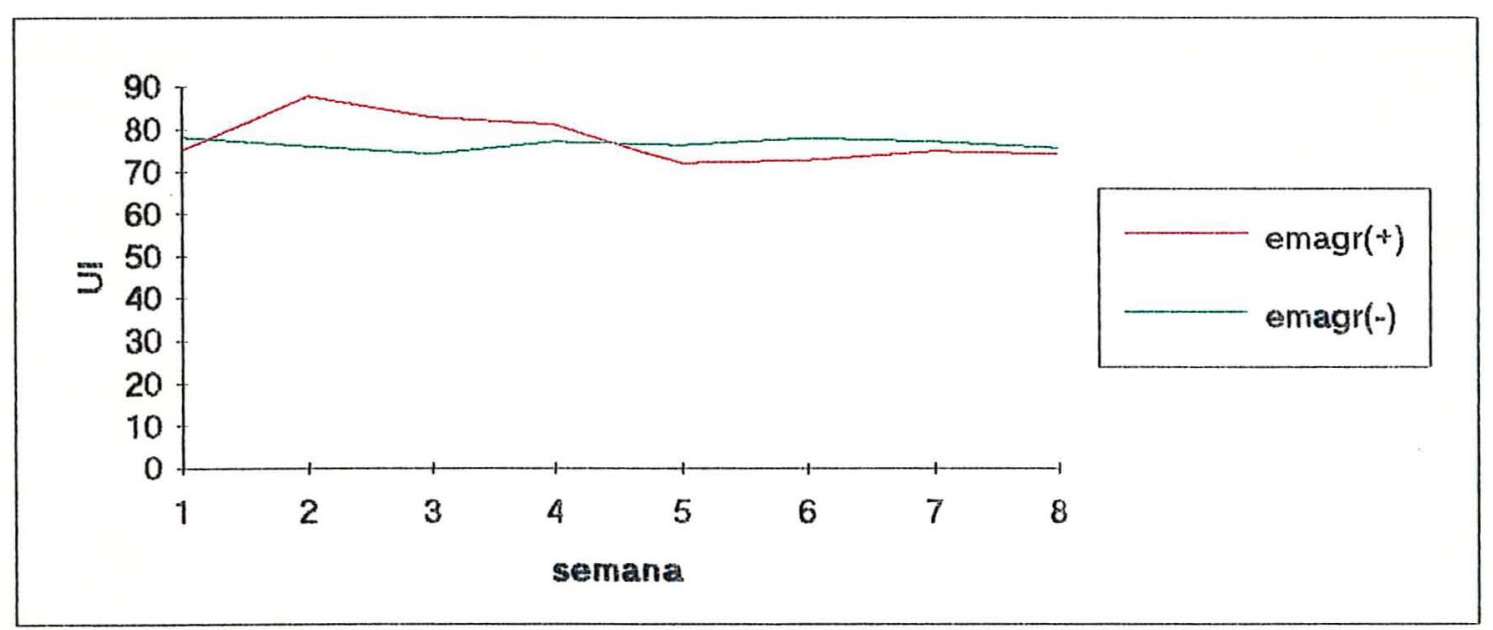

Fig. 20: Efeito de perda de peso sobre AST plasmática.

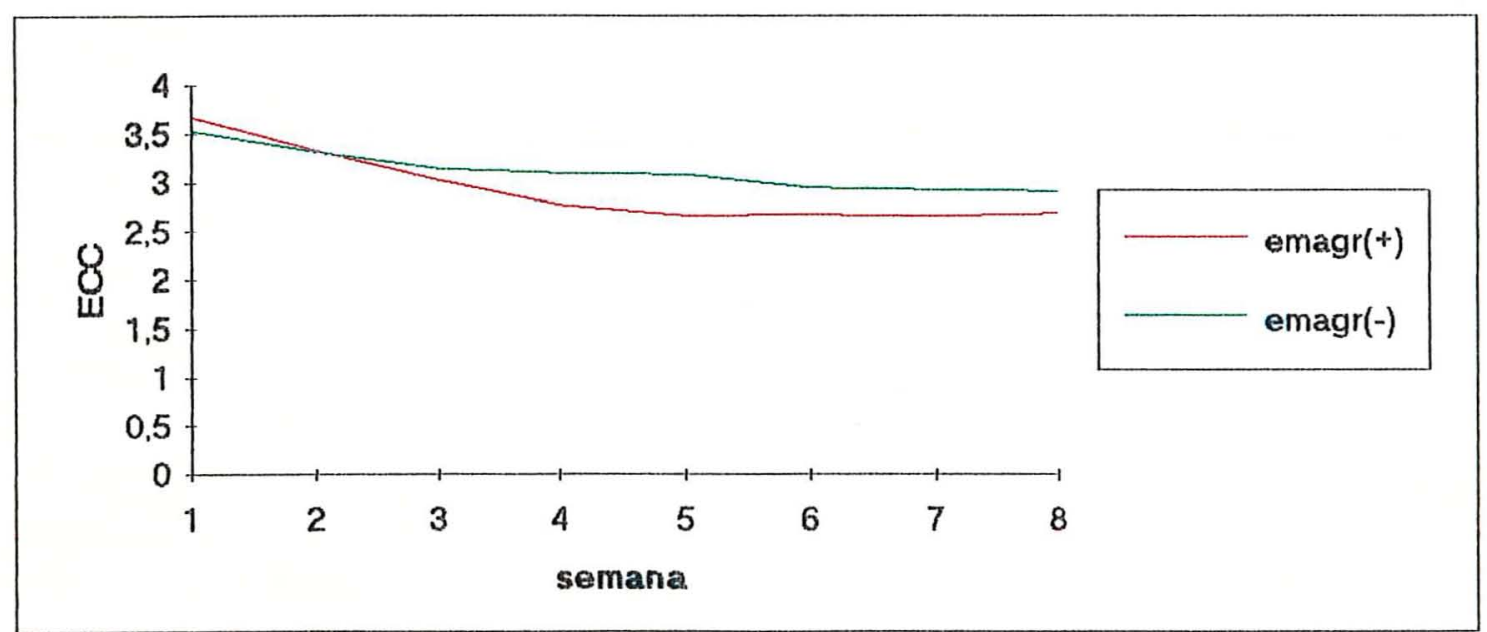

Fig. 21: Efeitode perda de peso sobre ECC. 


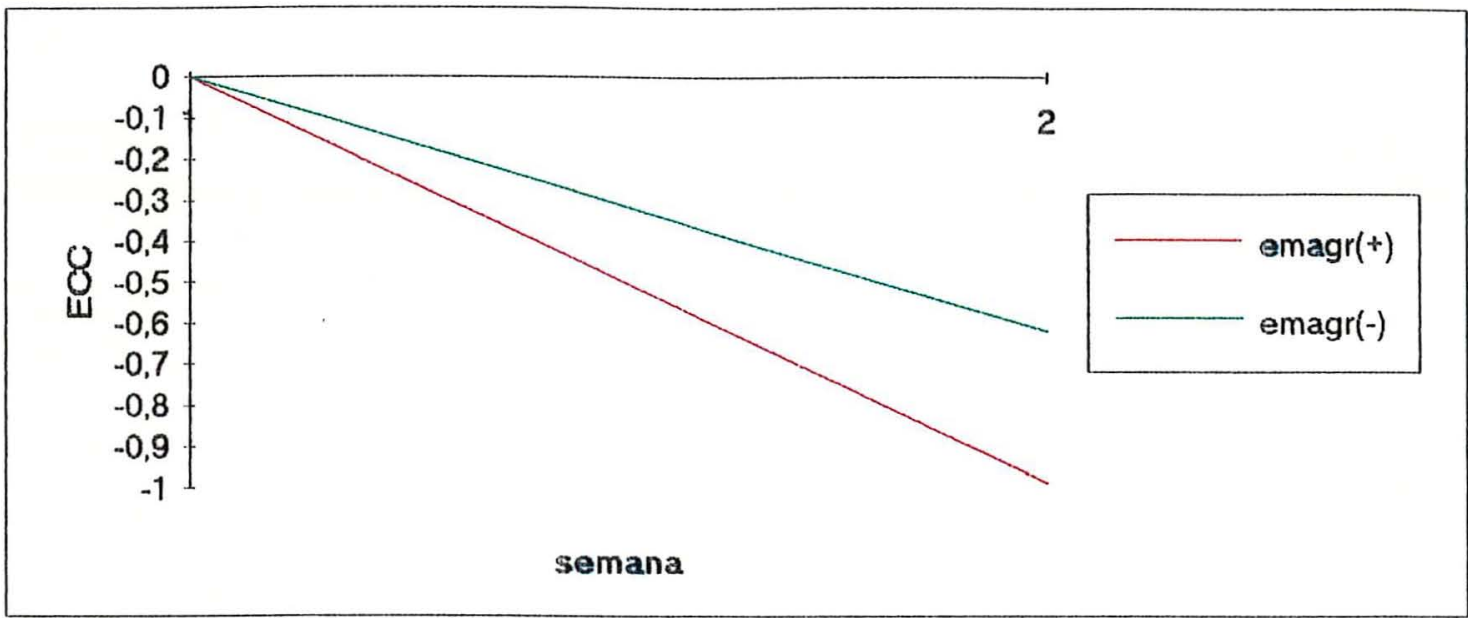

Fig. 22: Efeito de perda de peso sobre perda de ECC.

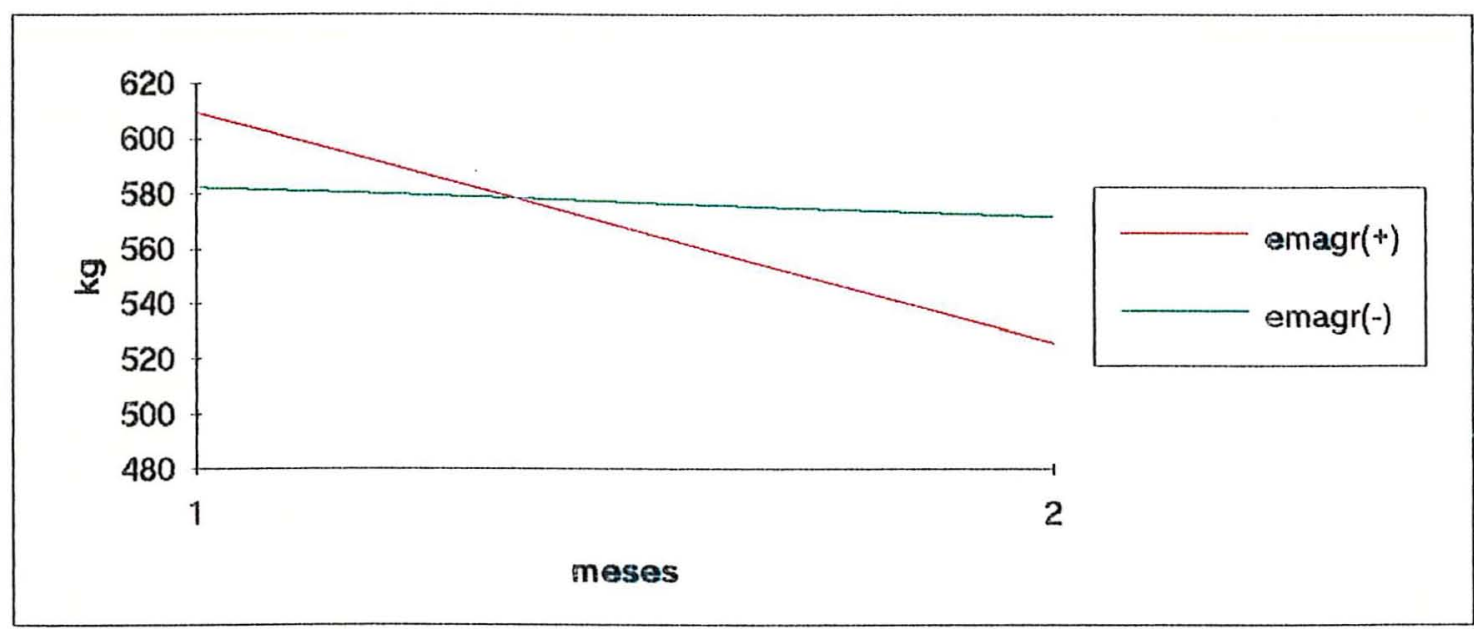

Fig. 23: Efeito de perda de peso sobre o peso. 